\title{
Research Paper \\ Analysis of Being Active Based on Older Adults' Experience: A Qualitative Study of Active Aging Strategies
}

Elham Mohammadi ${ }^{1}$, Talat Allahyari $^{1}$, Ali Darvishpoor Kakhaki ${ }^{2}$, Hasan Saraei ${ }^{3}$, Seyed Mohammad Fereshtehnejad ${ }^{4,5}$

1. Department of Social Work, Faculty of Social Sciences, Allame Tabataba'i University, Tehran, Iran.

2. Department of Nursing, School of Nursing \& Midwifery, Shahid Beheshti University of Medical Sciences, Tehran, Iran.

3. Department of Social Research, Faculty of Social Sciences, Allame Tabataba'i University, Tehran, Iran.

4- Department of Neurology and Neurosurgery, McGill University, Montreal, Canada.

5- Department of Neurobiology, Division of Clinical Geriatric, Care Sciences and Society (NVS), Karolinska Institute, Stockholm, Sweden.

\begin{tabular}{|c|c|}
\hline $\begin{array}{l}\text { Use your devicet toscan } \\
\text { and read the artice online }\end{array}$ & Chtation: Mohammadi E, Allahyari T, Darvishpoor Kakhaki A, Saraei H, Fereshtehnejad SM. [Analysis of Being Active Based on \\
\hline 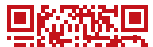 & Older Adults' Experience: A Qualitative Study of Active Aging Strategies (Persian)]. Iranian Journal of Ageing. 2017; 11(4):504-517. \\
\hline 24 & http://dx.doi.org/10.21859/sija-1104504 \\
\hline 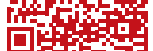 & doif: http://dx.doi.org/10.21859/sija-1104504 \\
\hline
\end{tabular}

Received: 6 Jun 2016

Accepted: 14 Nov. 2016

Key words:

Active aging, Strate-

gies, Grounded

theory, Active

attitude

\section{A B S TRACT}

Objectives In recent decades, it has become important to approach aging issues from the point of view that can ensure older adults' Quality of Life (QoL). As a result, countries have adopted a positive perspective with regard to aging, including active aging. The fact is that indigenous understanding of active aging is an unavoidable necessity for every society. Thus, the current study's aim was to understand active aging strategies based on older adults' experience.

Methods \& Materials This qualitative study, conducted during 2014-2016, used the Grounded theory method. It was initiated with the help of purposeful sampling and continued by way of applying theoretical sampling. The study field was cultural centers, artistic-cultural associations, and parks of Tehran. Data saturation was achieved through semi-structured interviews carried out among 35 elders. Data were analyzed and coded through coding suggested by the Strauss and Corbin method. Reliability of data was fulfilled in accordance with the Schwandt, Lincoln and Guba criteria.

Results Based on the experience of elders, active aging strategies consisted of 41 concepts, 7 subcategories, and 5 main categories. The categories and subcategories included primary strategies of isolation avoidance (not staying at home and interactionism), social participation (including continuity of career roles, volunteerism and institutional participation), strategies of active attitude and learning, physical activity and management of home's time and daily life

Conclusion Active aging requires applying strategies in 3 areas: elders' attitude, home environment, and society. For active aging in the country, practitioners and social planners need to strictly consider these 3 areas.

\section{* Corresponding Author:}

Talat Allahyari, PhD

Address: Department of Social Work, Faculty of Social Sciences, Allame Tabataba'i University, Tehran, Iran.

Tel: +98 (912) 2651952

E-mail: allahyari@atu.ac.ir 


\title{
تحليل تجربه سالمندان ساكن در اجتماع از فعالبودن: مطالعه كيفى استراتثىهاى سالمندى فعال
}

\author{
المبام محمدى'، "طلعت الهيارى'، على درويشيور كاخكى '، حسن سرايى'، سيد محمد فرشتهنزاد؟هه \\ 1 - كروه مددكارى اجتماعى، دانشكده علوم اجتماعي، دانشكاه علامه طباطبايي، تهرانه ايران.

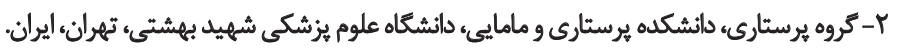

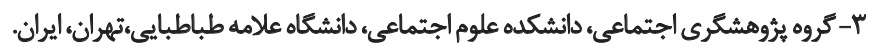

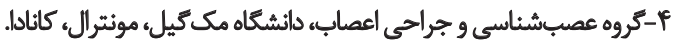

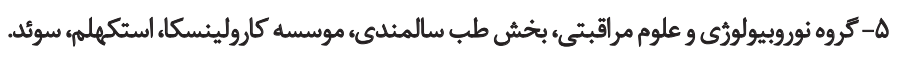

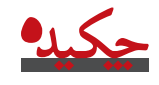

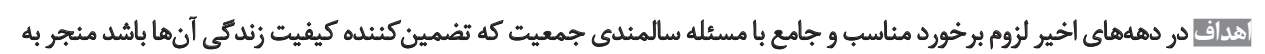

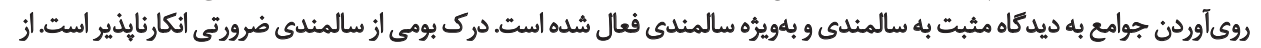

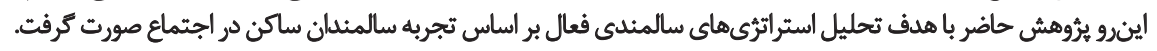

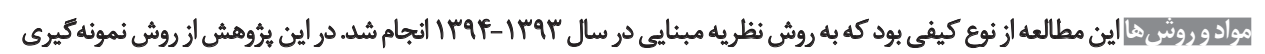

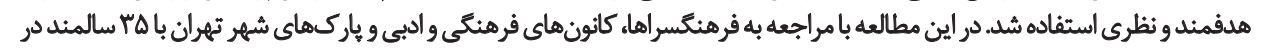

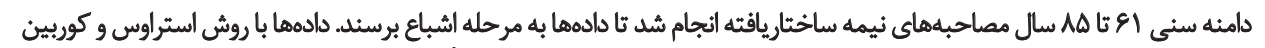

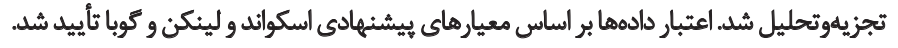

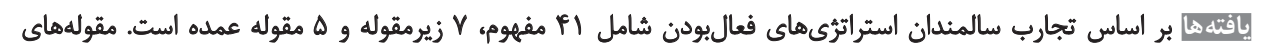

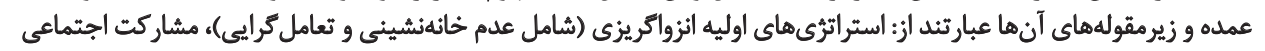

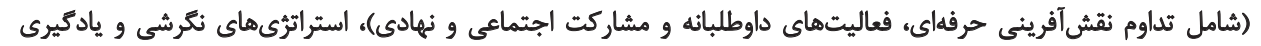

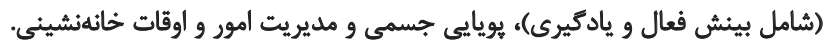

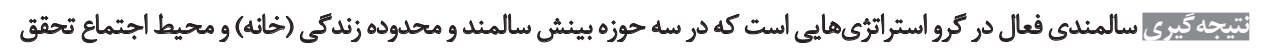

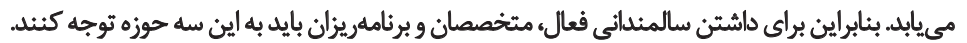

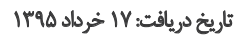

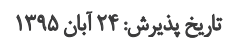

\section{كليدوازّها:

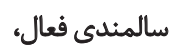 استرائزي، نظريه مبنايى، بينش فعال}

و خوب. همه اين عناوين يك بيام مشترك و قوى را دارند. doleto

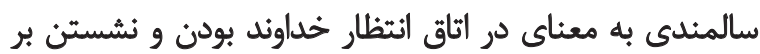

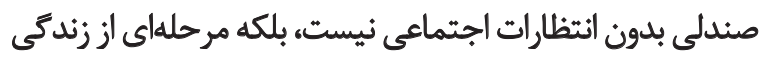

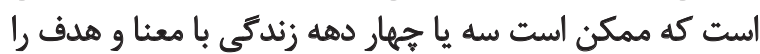

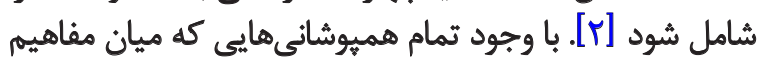

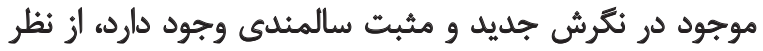

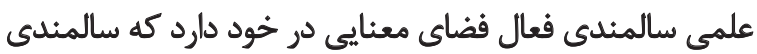

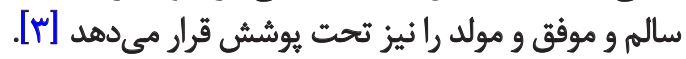

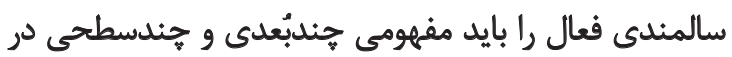

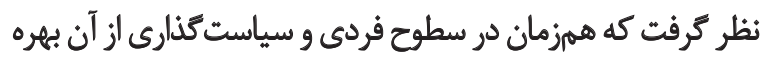

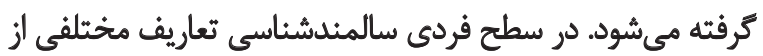
سالمندى فعال يا به عبارت دقيقتر فعال بودن در دوره سالمندى نعائي

در كذشته به سالمندى جمعيت به صورت سنتى به عنوان

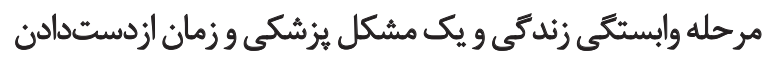

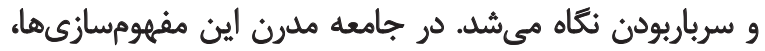

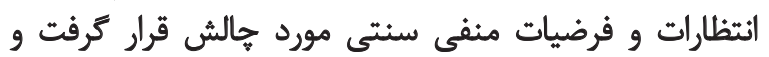

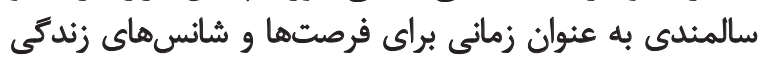

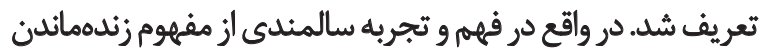

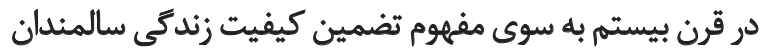
در قرن بيست و يكم تغيير رخ داده است [1]

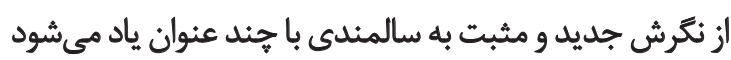

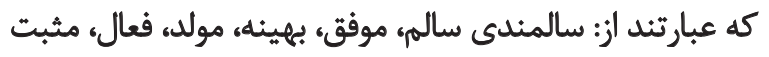


فعال به عنوان يك استراترّى و نيز فقدان تعاريف موجب شده أنها

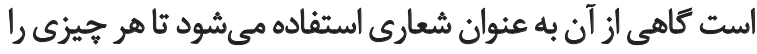

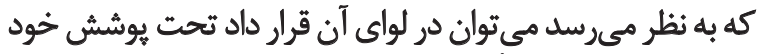

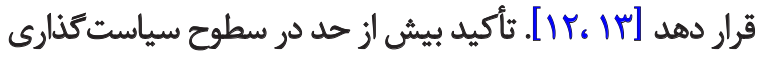
بر سالمندى فعال موجب شده است اين مسئله كه سالمئد المدان

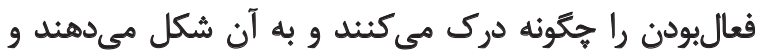

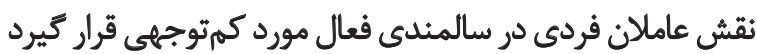

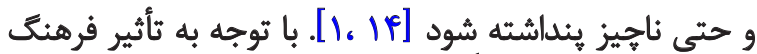

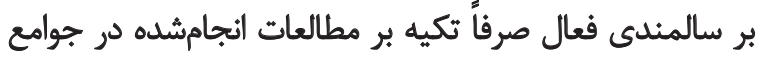

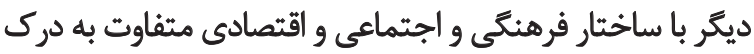

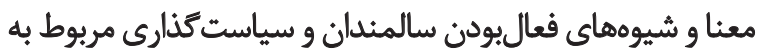
سالمندى فعال كمك نمى كند [1هال

با توجه به اينكه براى شناخت و درك بهتر وضعيت جمعيت

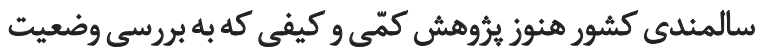

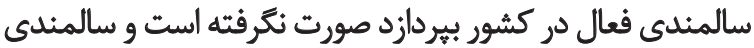

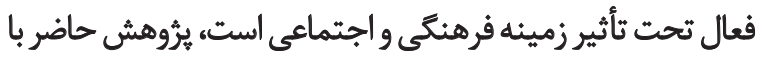

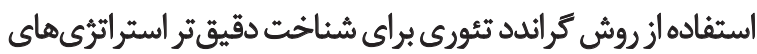
فعال بودن بر اساس تجربه سالمندان انجام شده است

\section{روش مطالعه}

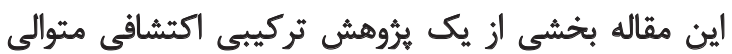

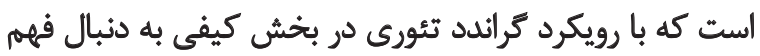

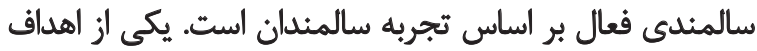

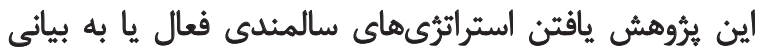

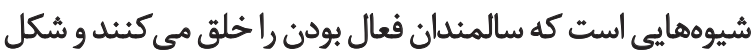

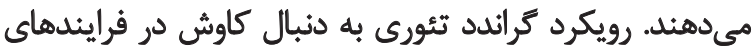

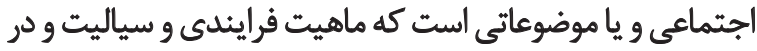

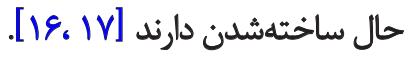

در اين يُروهش ميدان مطالعه شامل كانونهاي جهان فانديدَّان

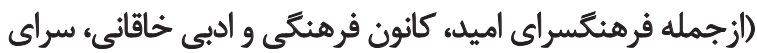

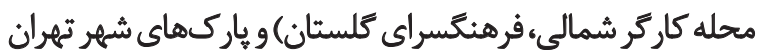

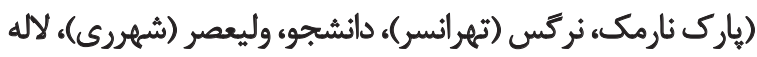

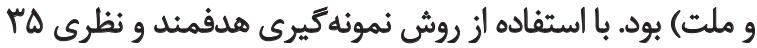

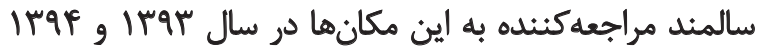

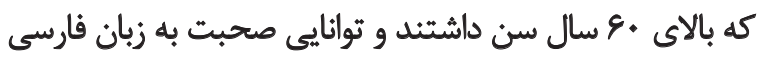

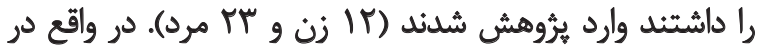

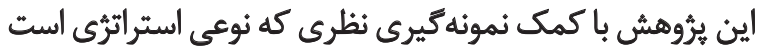

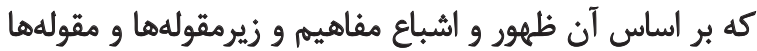

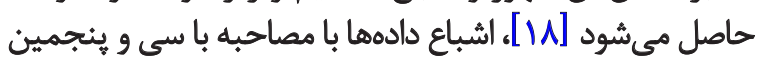

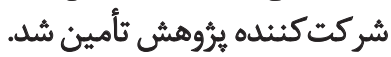

براى انجام اين يُروهش بعد از گرفتن معرفى نامه براى حضور

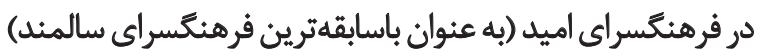

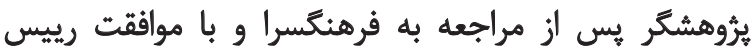

شده است. مولارت و وياريس' [F] در بررسى تعاريف سالمندى

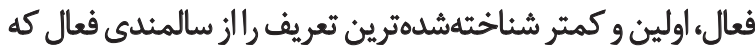

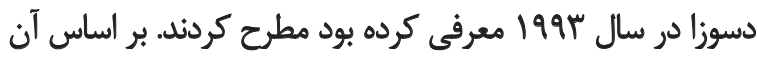

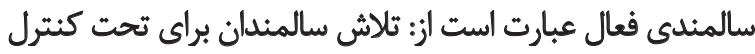

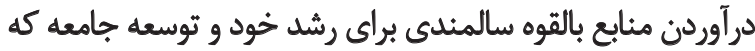

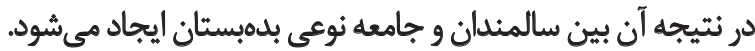

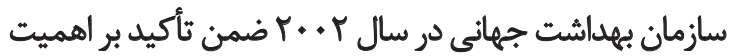

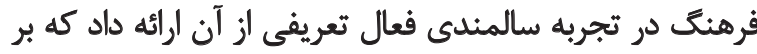

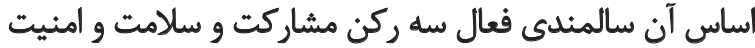

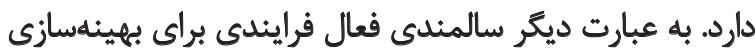

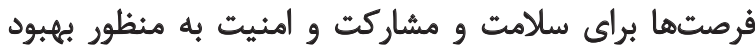

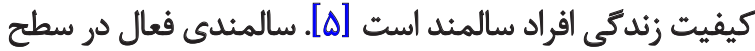

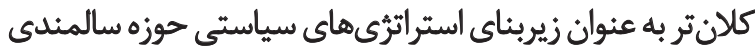

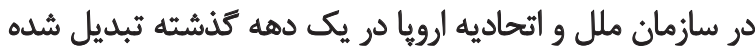

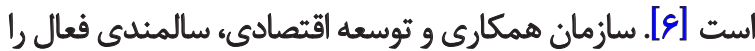

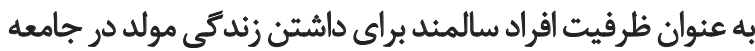
و واقتصاد تعريف مى كند. تمركز اين سياست افزيت برايش سالمندان

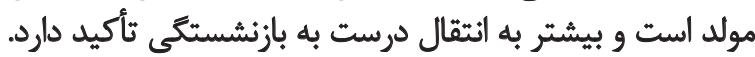

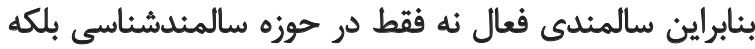

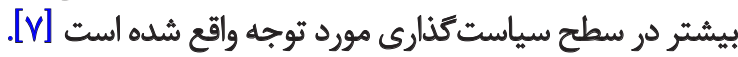

ايرؤوهشهاى مختلف در زمينه درك سالمندى فعال و فرايند

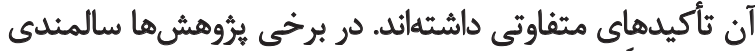

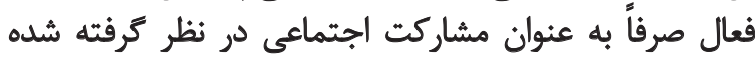

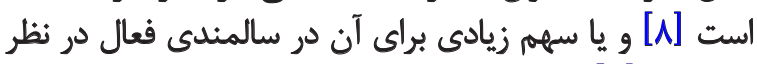

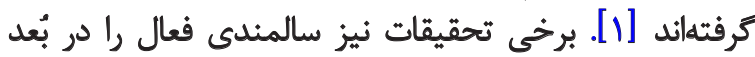

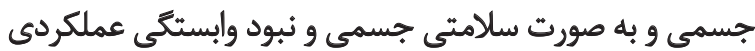

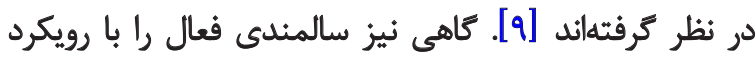

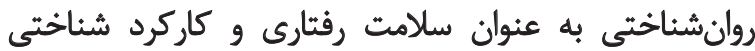

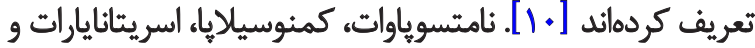

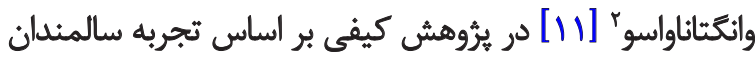

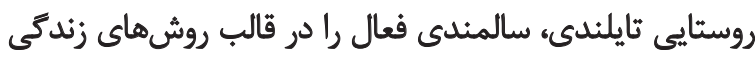

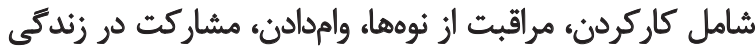

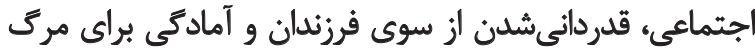

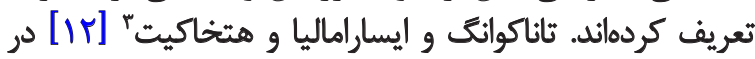

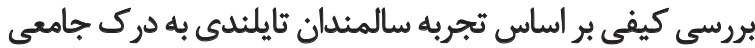

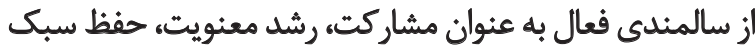
زندكى سالم، يادكيرى فعال و امنيت دست يافتهان رشنداند.

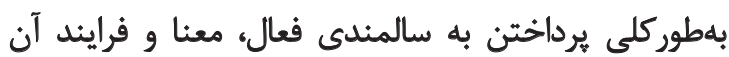
همواره با جالشهايى مواجه بوده است. عدم ائسجام سالمندى فران

1. Moulaert \& Paris

2. Namtsupawat, Kamnusailapa, Sritanyarat \& Wongthanawasu

3. Thanakwang, Isaramalai \& Hattkhakit 


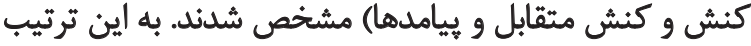

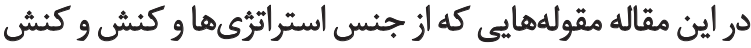

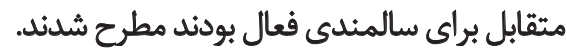

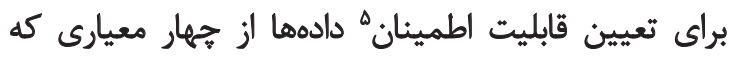

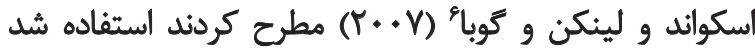

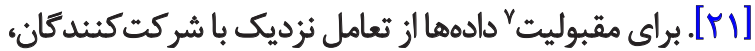

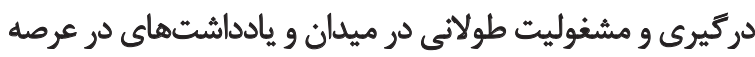

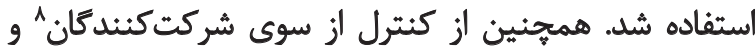

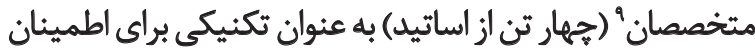

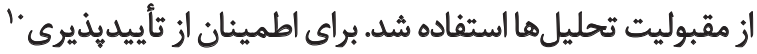

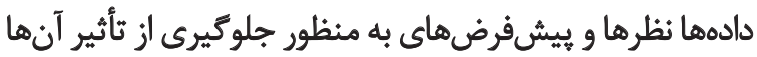

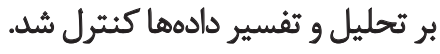

با ارائه توصيف دقيق از شركت كنيندان، روند يثوهش، اقدامات

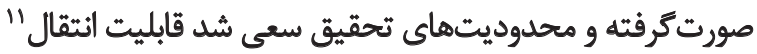

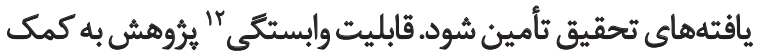

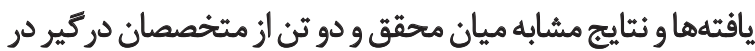

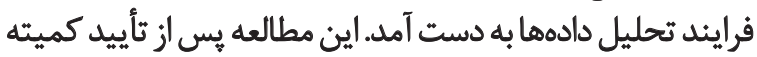

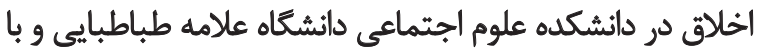

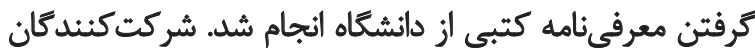

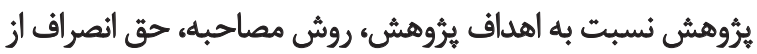

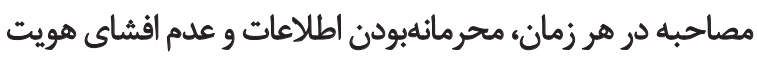

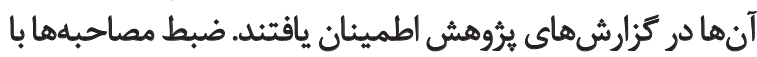

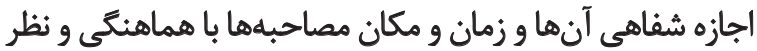
آنها صورت كرفت آنهاه

يافتهها

شركت كثند كان يُووهش كه همثى سالمندان ساكن در اجتماع

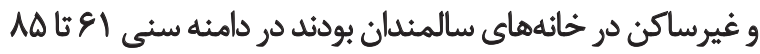

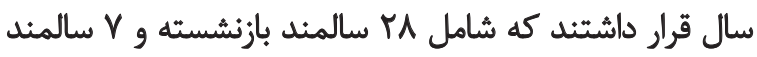

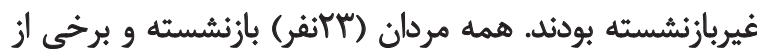

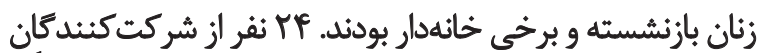

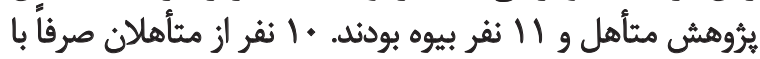

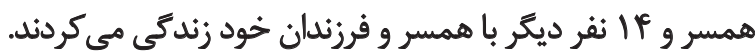

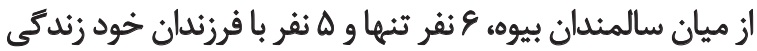

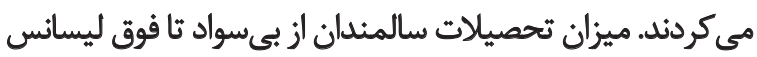

5. Trustworthiness

6. Schwandt, Lincoln \& Guba

7. Credibility

8. Peer check

9. Expert check

10. Conformability

11. Transferability

12. Dependability
فرهنكسرا به جند سالمند به عنوان مطلعان كليدى معرفي شد.

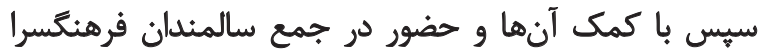

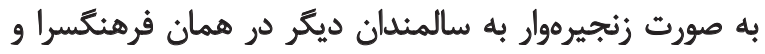

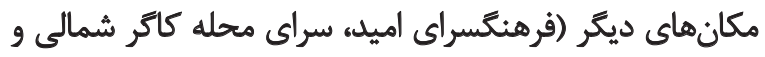

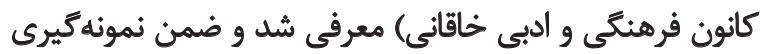

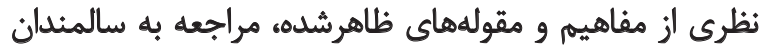

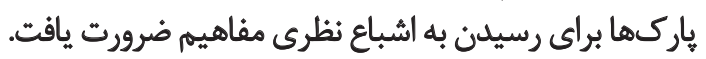
روش اصلى جمعآورى دادهها مصاحبه نيمه ساختاريافتنه بود،

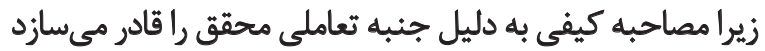

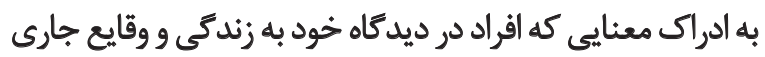

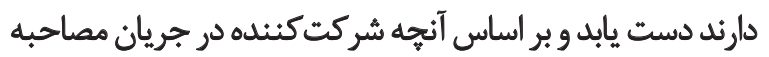

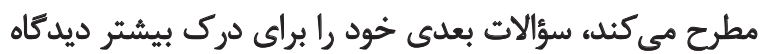

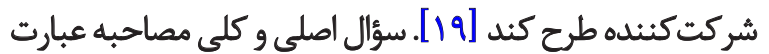

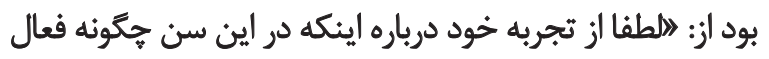

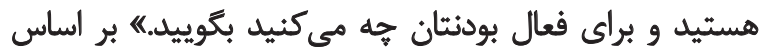

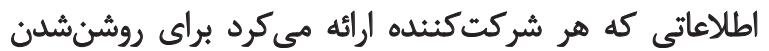

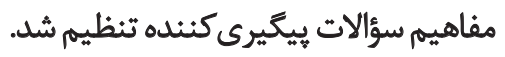

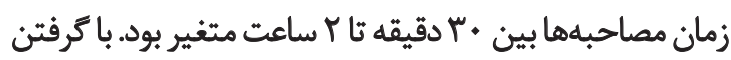

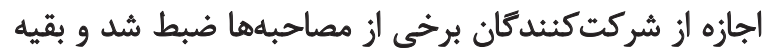

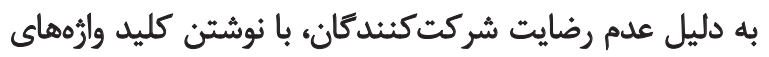

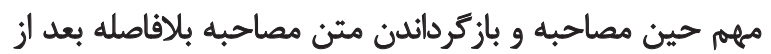

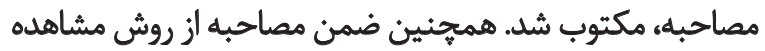

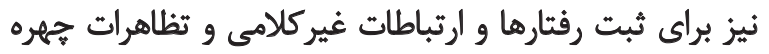

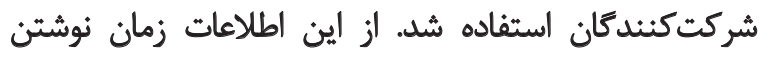

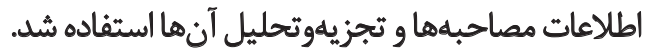

جمع آورى و تجزيهوتحليل دادهها بر اساس روش كرانداندئئورى

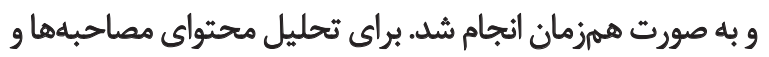

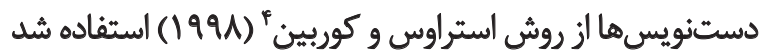

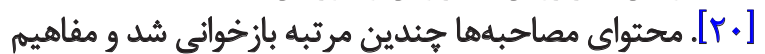

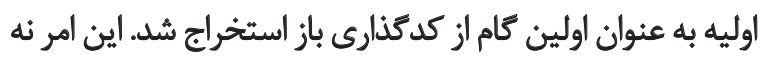

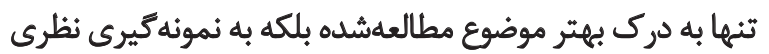

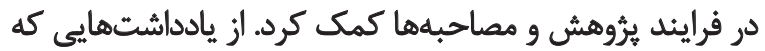
شامل اطلاعاتى براى درك بهتر مفاهيم بود نيز استفاده شد.

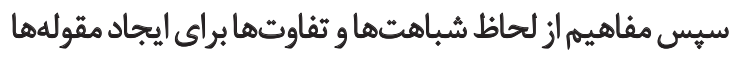

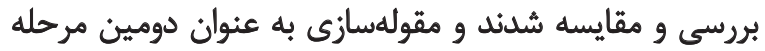

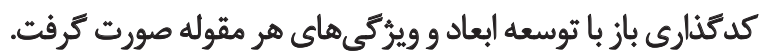

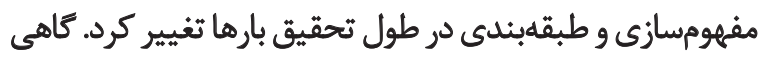

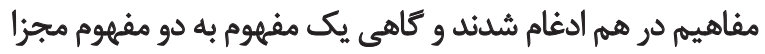

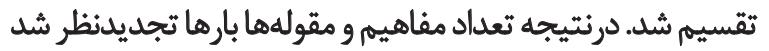

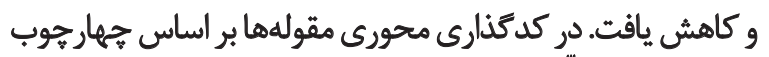

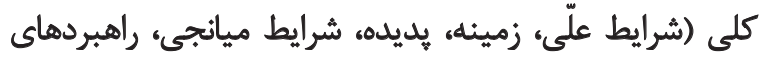

4. Strauss \& Corbin 
است. جه جيزهايى آمده. بهتر از اين است كه خانه بمانمه《ه

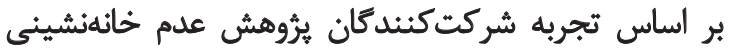

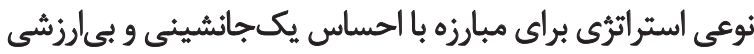

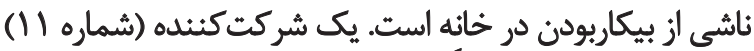

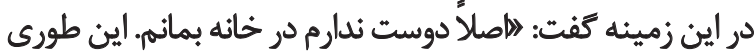

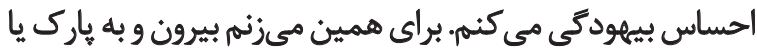

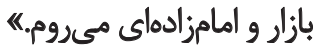

\section{زيرمقوله تعامل}

زيرمقوله تعامل گرى شامل مفاهيم مشغوليت در تعاملات

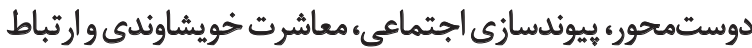

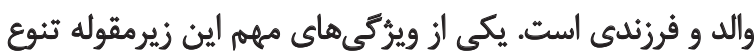

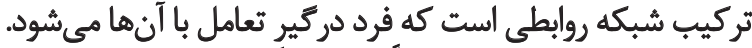

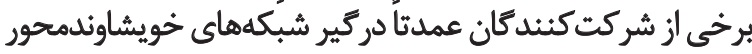

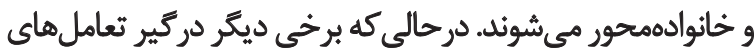

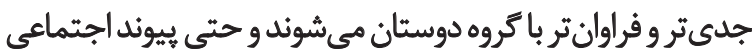

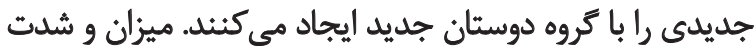

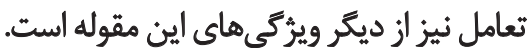

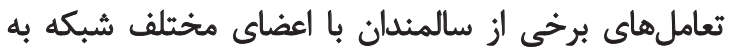

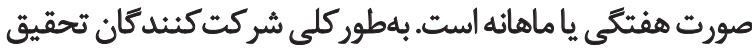

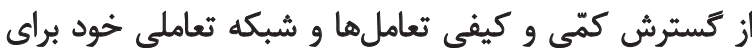

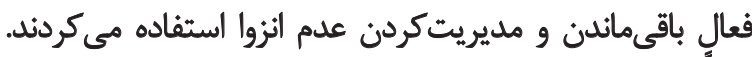

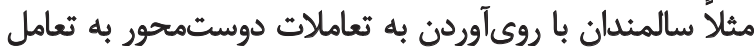

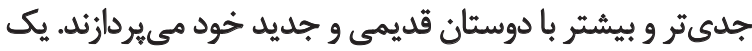

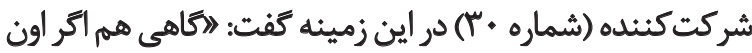

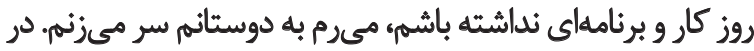

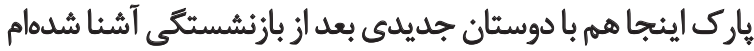

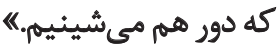

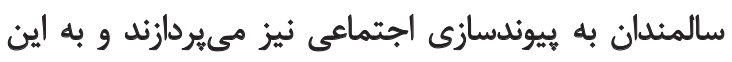

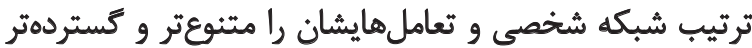

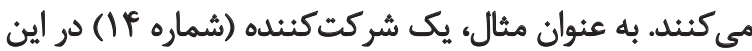

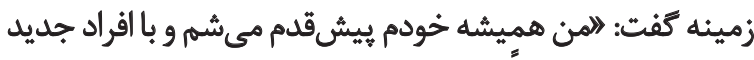

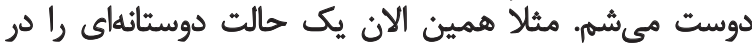

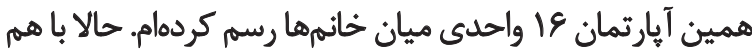

دوستيه و كارهاى زيادى را انجام مي ميديم"

معاشرت با خويشاوندان و رابطه والد و فرزندى يكى ديكر انواع تركيب شبكه شخصى سالمندان است كه در آن سالمندان بان بان بان

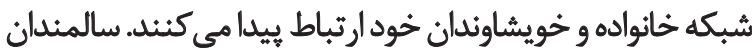

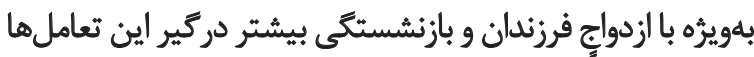

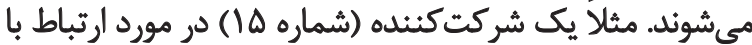

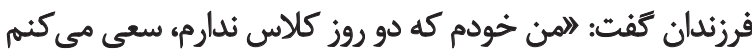

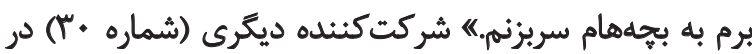

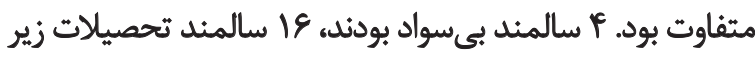

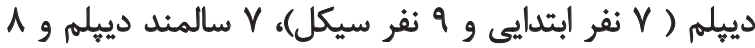

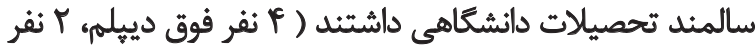
ليسانس و r نفر فوق ليسانس).

وضعيث اقتصادى شركت كنيدكان با توجه به ميزان كفايت

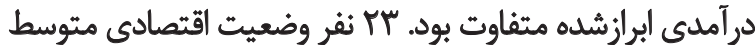

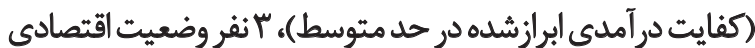

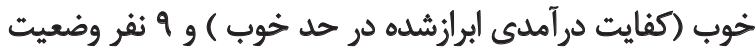
اقتصادى ضعيف (كفايت درآمدى ابرازشده در حد حدم) داشيت داشتند.

بر اساس تحليلهاى صورت كرفته در كدكذارى باز و محورى،

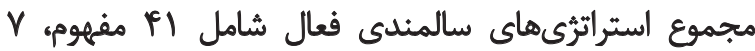

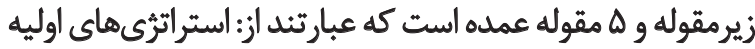

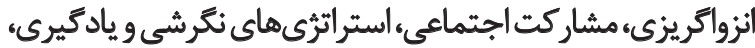

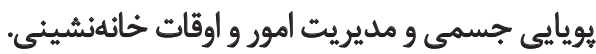

\section{استراترىهاي اوليه أنزواتئريزى}

اين مقوله اصلى از دو زيرمقوله مهم عدم خائهنشينى و

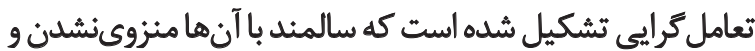
فعال ماندن خود را مديريت تشكيل شيد المند.

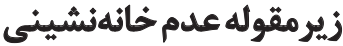

مفاهيم پاركنشينى و كردش روزانه و عدم خانهنشينى

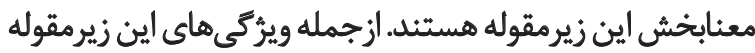

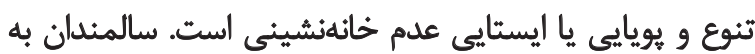

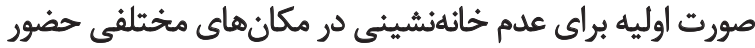

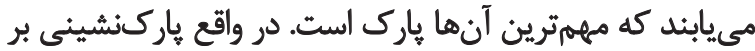

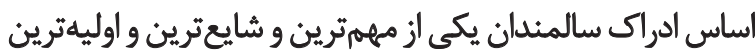

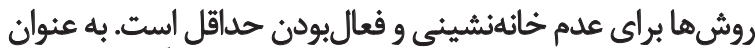

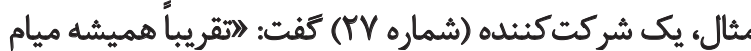

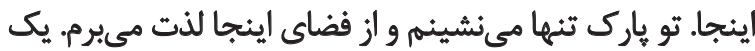

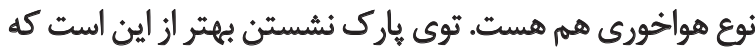

أدم توى خائه بماند و بيرون نرود.

كردش در شهر يعنى دورشدن از محل زندكى و روفتن بـ به مناطق

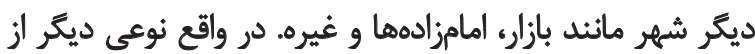

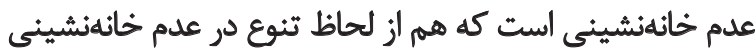

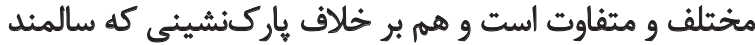

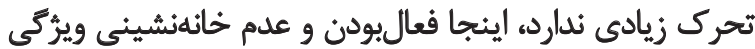

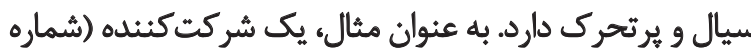

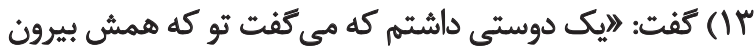

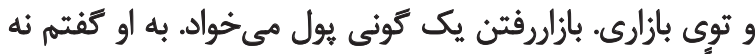

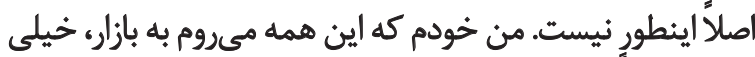

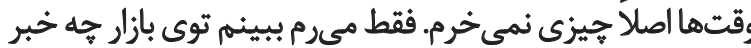




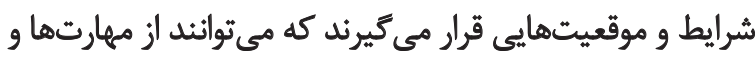

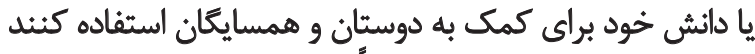

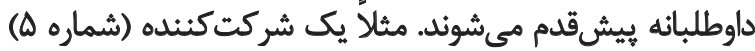

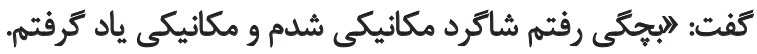

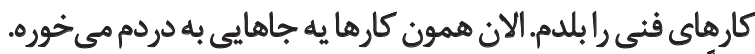

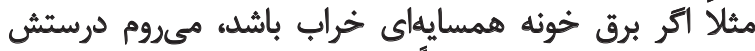

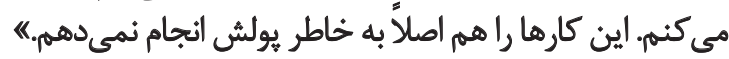

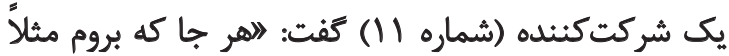

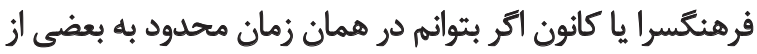

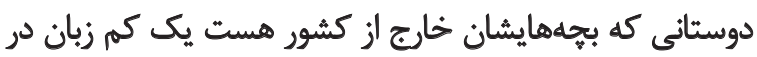

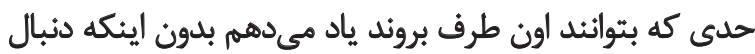

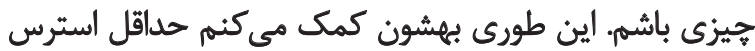
كمترى داشته باشند.

بر اساس تجربه سالمندان بى تفاوت نماندن و داشتن حساسيت

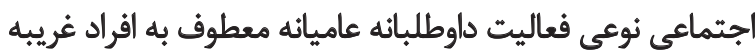

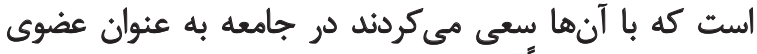
فعالتر باشند. مثلاً يك شركت مكنئده (شماره

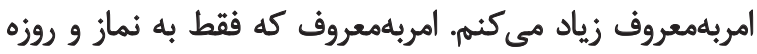

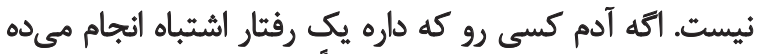

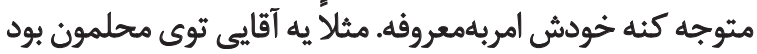

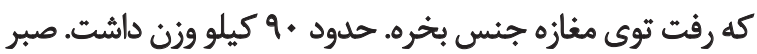

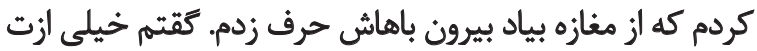

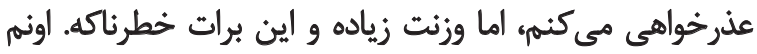

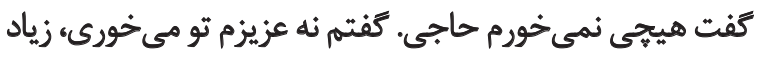

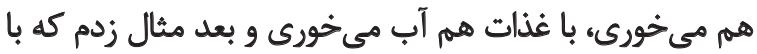

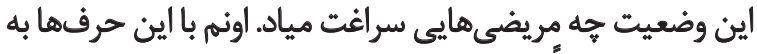

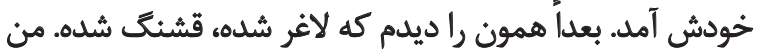

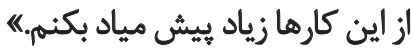

برخى از سالمندان با نتهبدارى داوطلبانه از نوهها يا كودكان

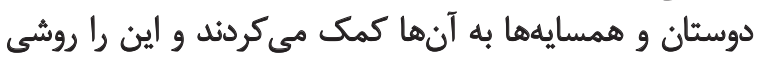

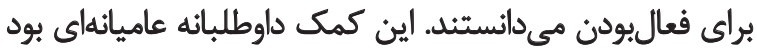

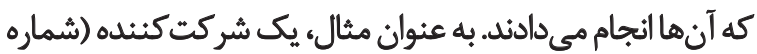

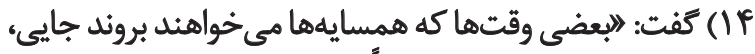

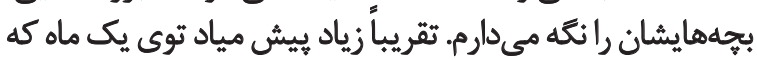

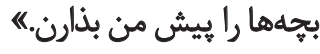

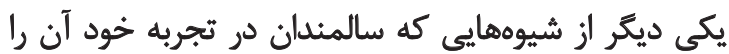

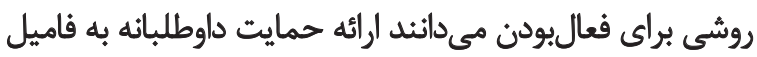

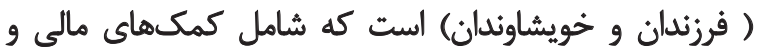

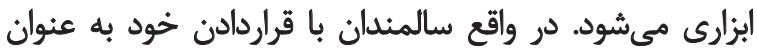

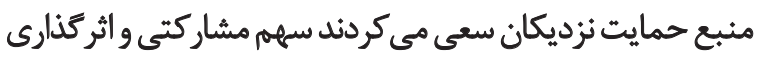

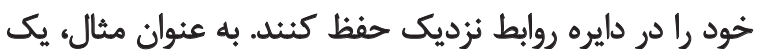

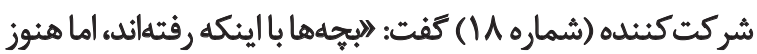

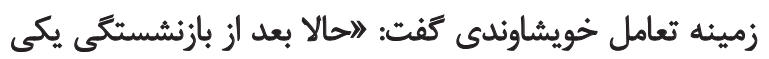

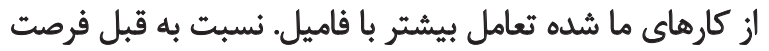

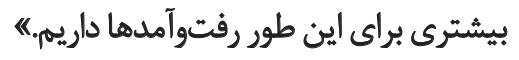

مشاركت إبتماعى

مقوله اصلى مشاركت اجتماعى از سه زيرمقوله فعاليتهاى

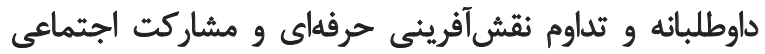

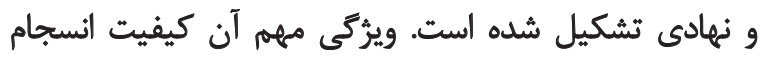

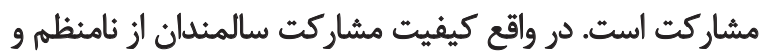

سازمانئيافته تا سازمانيافته و منظم و نهادي تثاوت مثات دارئ

زيرمقوله فعاليتهاى داوطلبانه

زيرمقوله فعاليتهاى داوطلبانه به يكى از شيوههاى مهام إزماريم

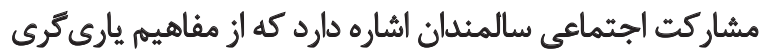

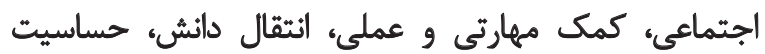

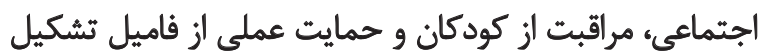

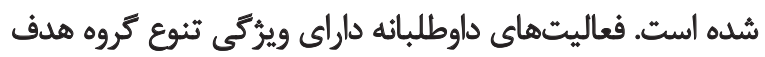

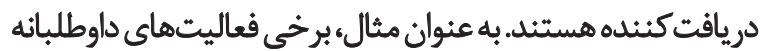

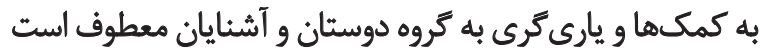

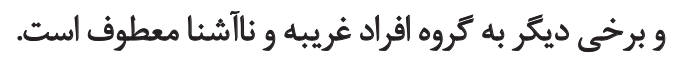

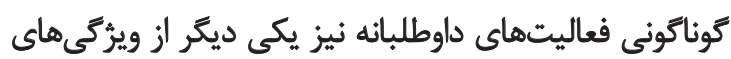

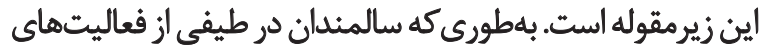

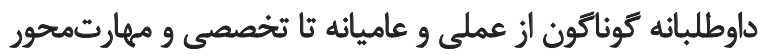

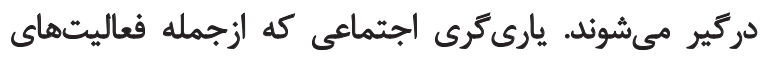

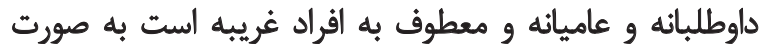

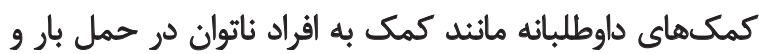

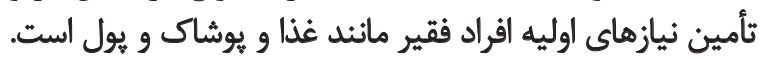

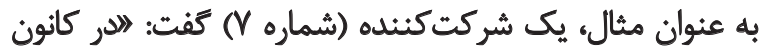

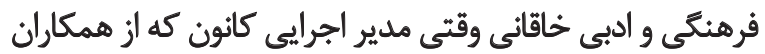

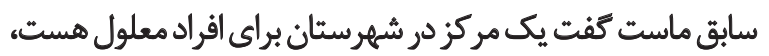

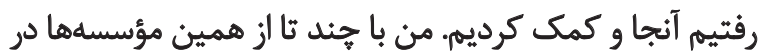

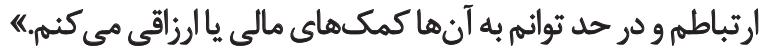

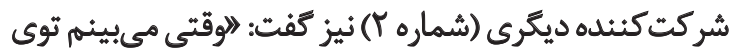

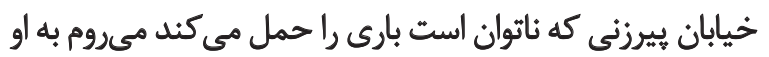

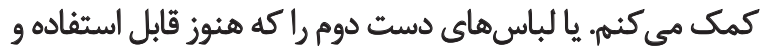

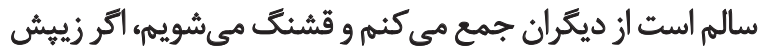

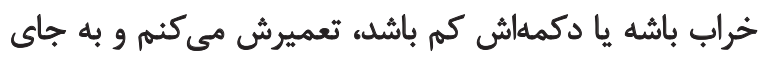

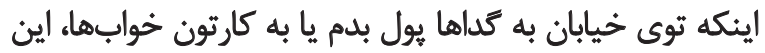
لباسها را بهش مي خدم تا استفاده كنه.

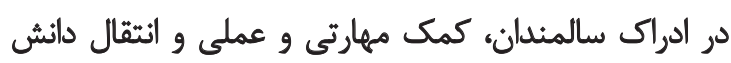

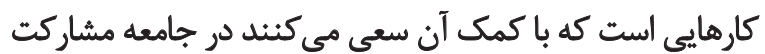

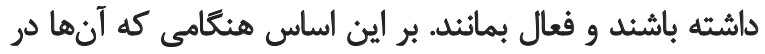


جلساتشان به عنوان نماينده حاضر شوم.《

\section{زيرمقوله مشاركت اجتماعى ونهادى}

مشاركت اجتماعى و نهادى يكى ديكر از زيرمقولههاى مشاركت

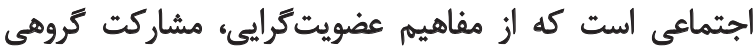

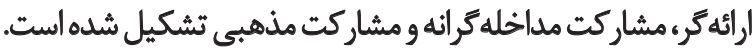

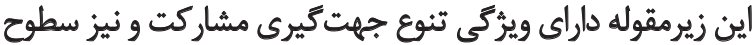

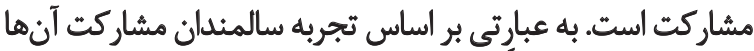

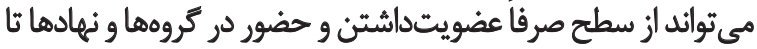

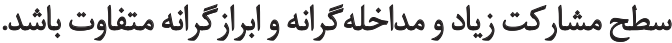

سمتوسوى مشاركتها ممكن است معطوف به حوزه مذهبي

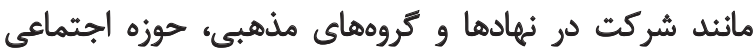

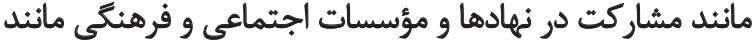

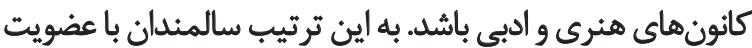

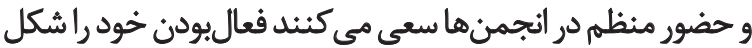

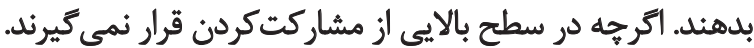

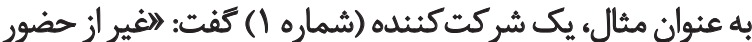

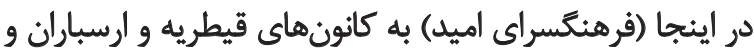

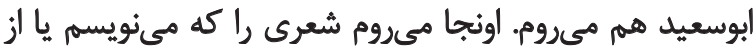

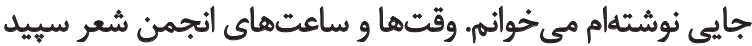
را مى دانم. مىروم آنجا مى خئشينه. فقط همين." مشاركتجويى مذهبي بر اساس تجربه سالمندان عمدتاً در

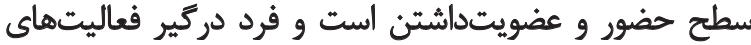

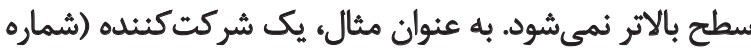

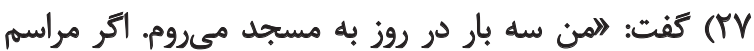

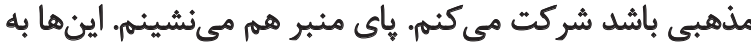

نوعى بودن در جاهعd است.

بر اساس تجربه سالمندان مشاركت منظم سازمانيافته كه

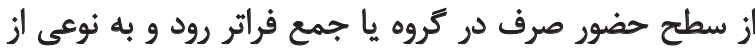

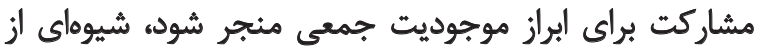

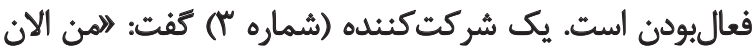

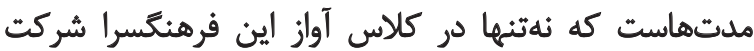

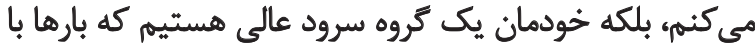

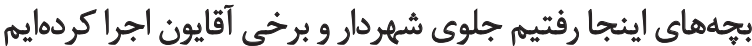

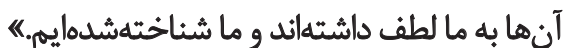

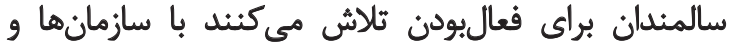

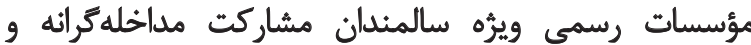

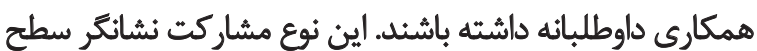

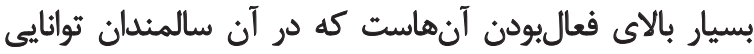

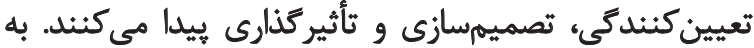

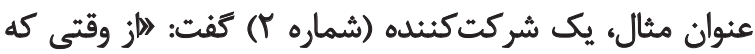

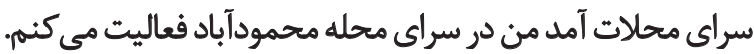

كارهاي ادارىشان رامن انجام مي دهم و دنبال كارهايشان ميروم

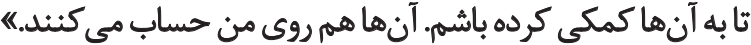

\section{زيرمقوله تداوم نقش آفرينى حرفهاى}

زيرمقوله تداوم نقش آفرينى حرفهاى متشكل از مفاهيم اشتغال

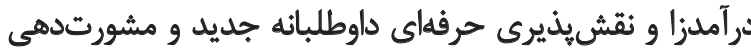

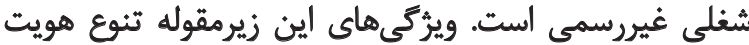

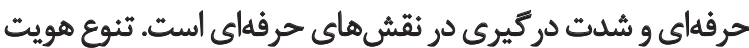

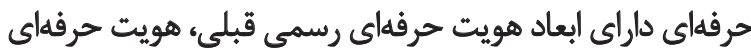

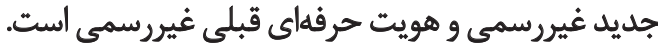

شدت دركيرى سالمندان در نقش آفرينى حرفهاى از درئيرى

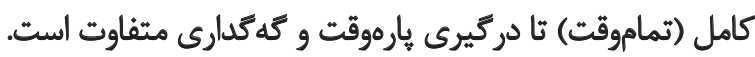

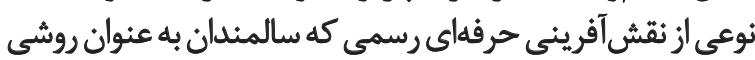

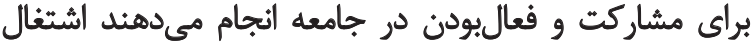

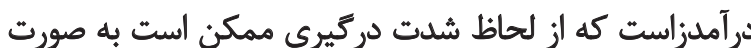

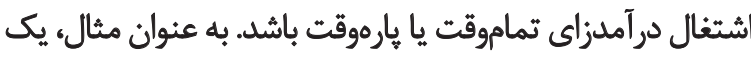

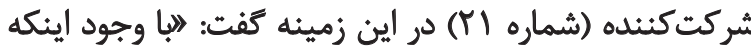

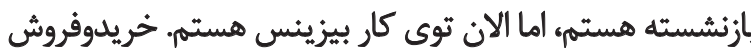

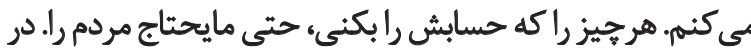

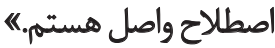

مشورتدهى شغلى غير رسمى نوعى از نقشى آفرينى حرفهاي به

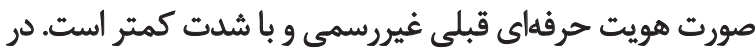

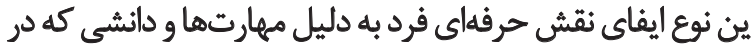

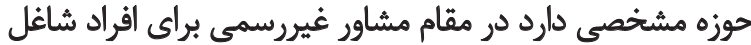

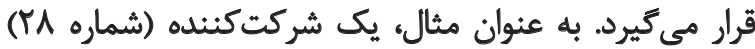

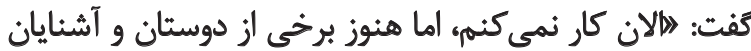

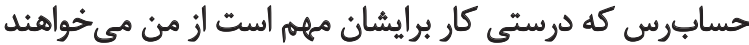

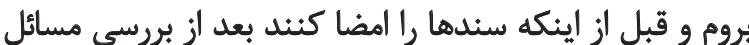

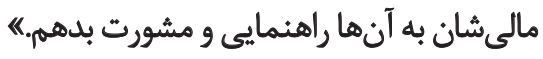

نقشئيرى حرفهاى جديد داوطلبانه بر اساس تجربه سالمندان

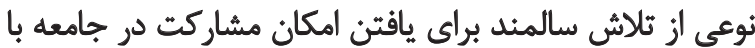

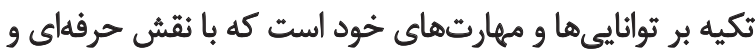

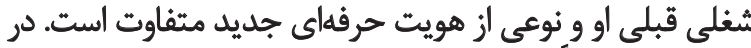

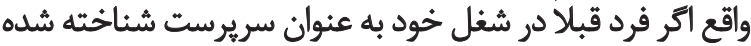

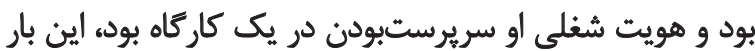

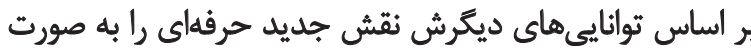

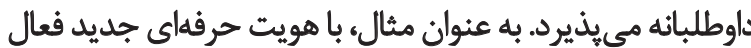

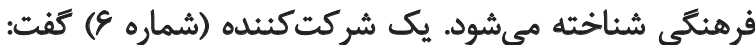

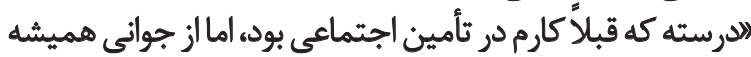

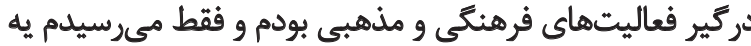

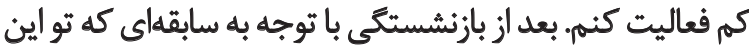

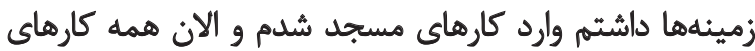

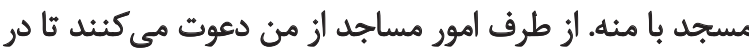


زنده نكَداشتن خيال ها و آرزوها كه به معناى نتاهي اميدوار و

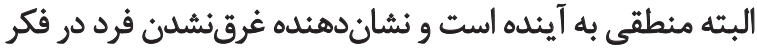

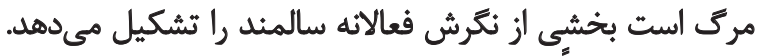

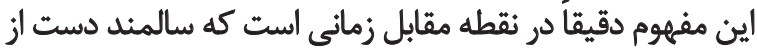

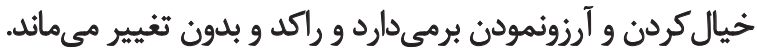

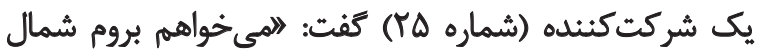

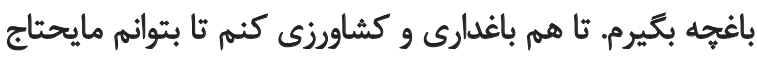

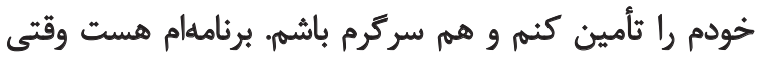

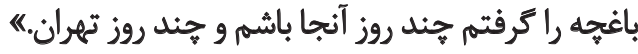

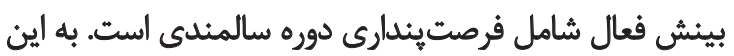

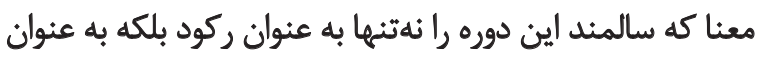

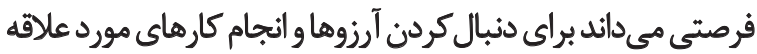

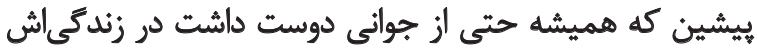

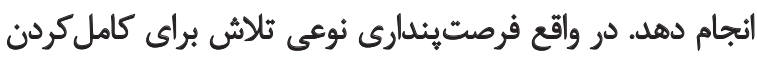

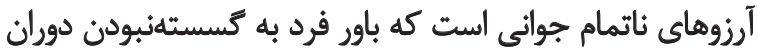

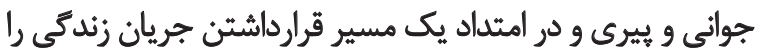

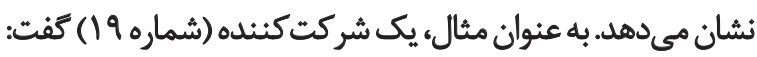

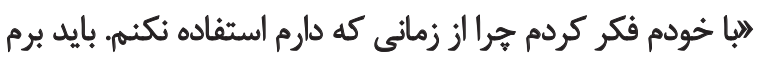

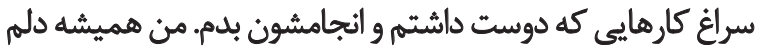

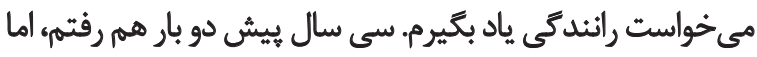

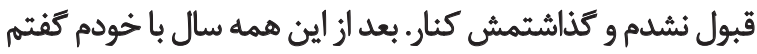

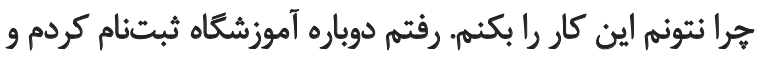

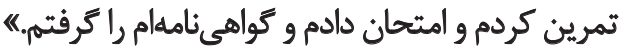

\section{زيرمقوله يادكيرى}

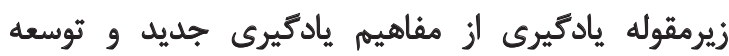

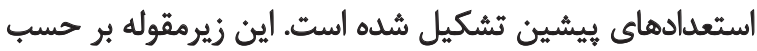

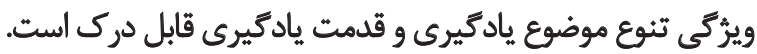

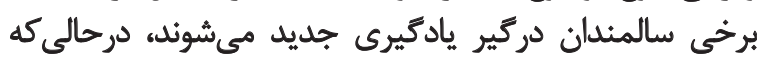

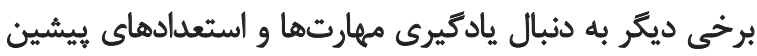

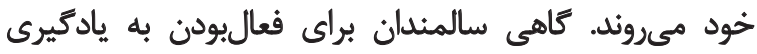

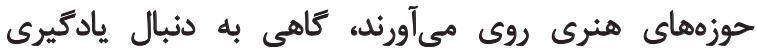

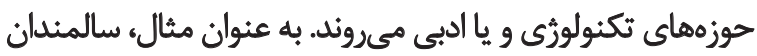

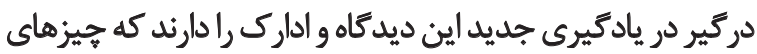

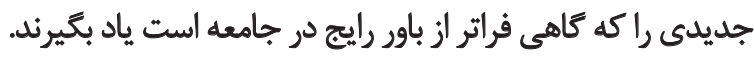

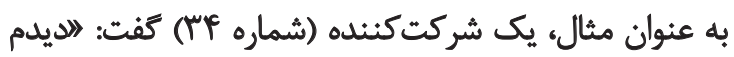

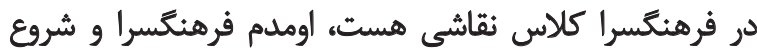

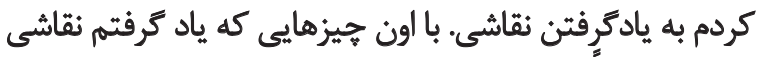

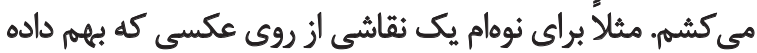

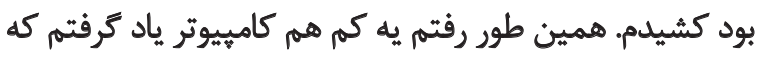

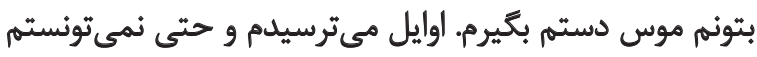

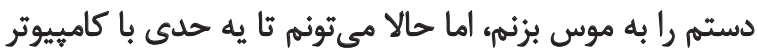

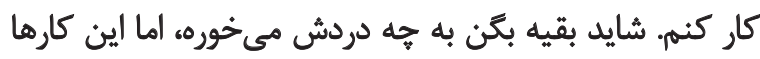

در سراى محله جهاد هم هستم و در آنجا براى مردم مخصوصاً

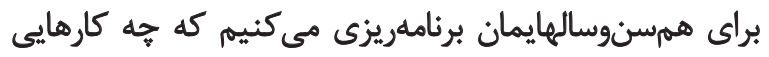

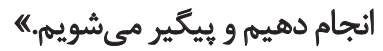

\section{استراتثى هاى نكّرشي و يادَّيرى}

مقوله اصلى استراترى نترشى و يادكيرى از دو زيرمقوله بينش

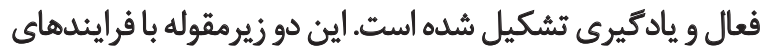

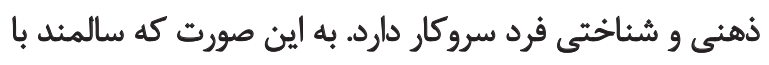

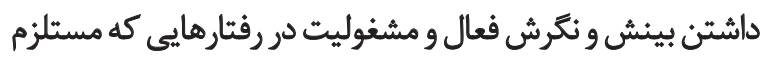

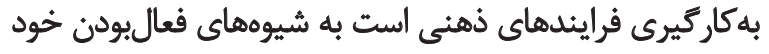

$$
\text { los }
$$

\section{زيرمقوله بينش فعال}

زيرمقوله بينش فعال از مفاهيم برنامهريزى ذهنى، فراتر رفتن

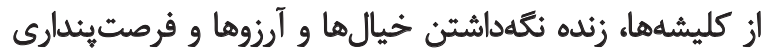

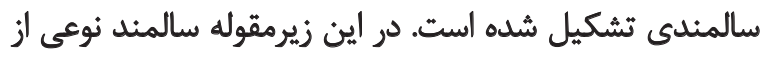

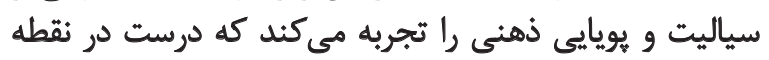

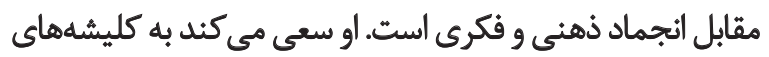

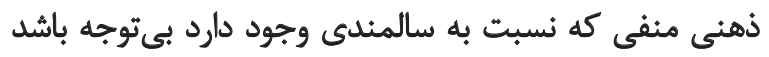

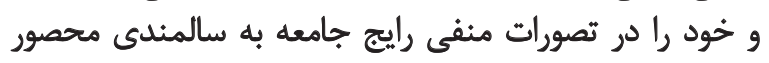

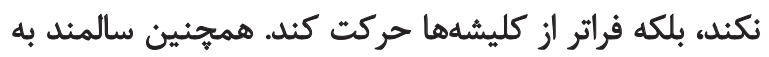

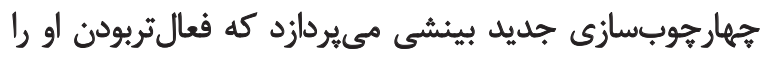

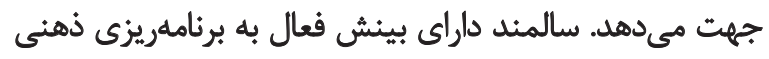

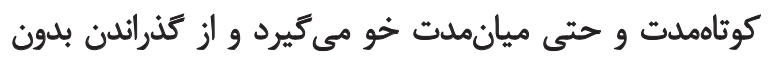

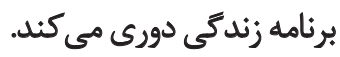

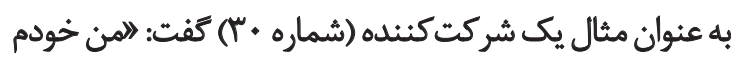

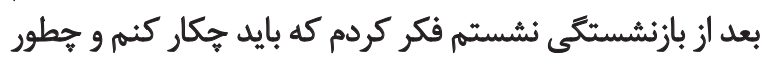

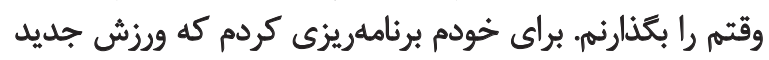

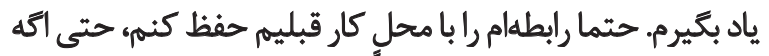

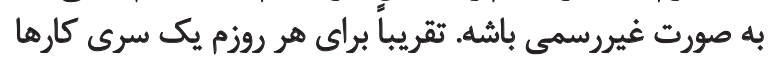

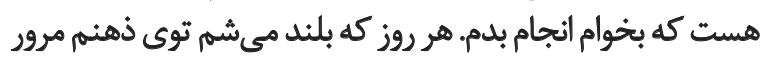

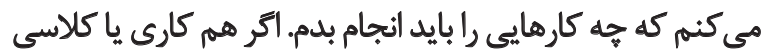

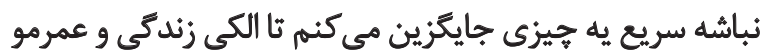
حتى براى يه روز هم هدر ندم. بائه

فراترفتن از كليشههايى كه عمدتاً ديد كاهى منفى به سالمندى

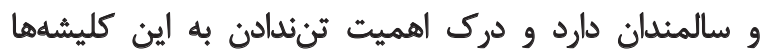

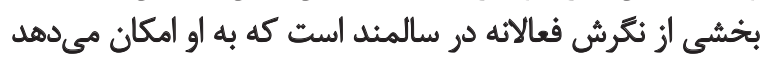

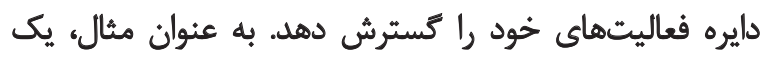

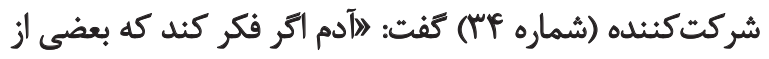

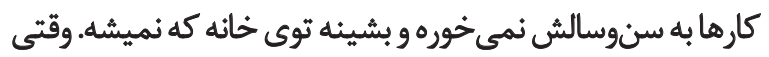

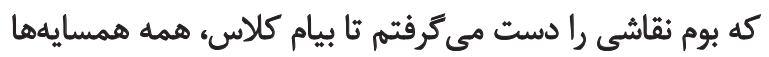

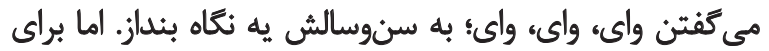

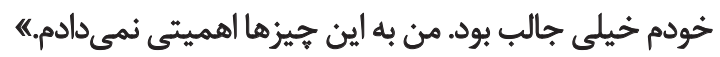


مديريت امور و اوقات خائهنشينى

مقوله اصلى مديريت امورو اوقات خانهنشينى علاوه بر مقوله بهاى

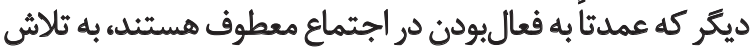

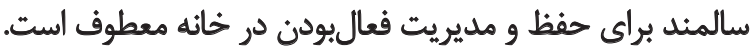

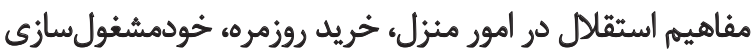

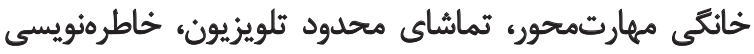

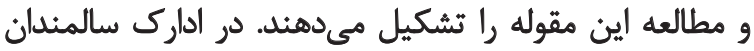

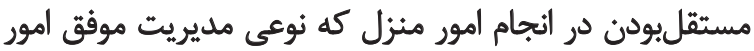

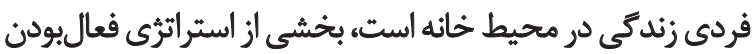

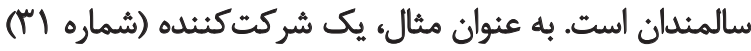

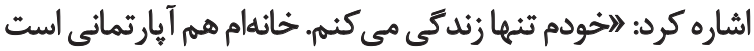

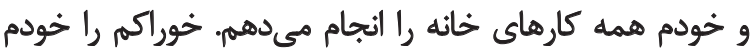

$$
\text { حاضرى درست مى كنمه " }
$$

همجينين استقلال و توانايى انجام خريد منزل يكى ديكر از

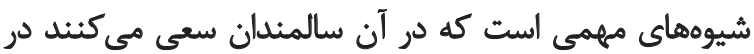

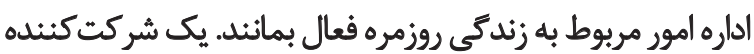

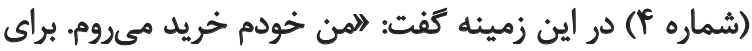

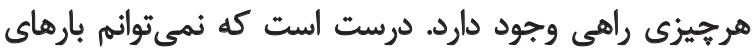

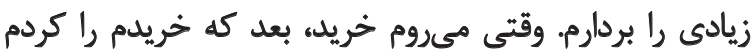

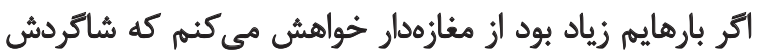

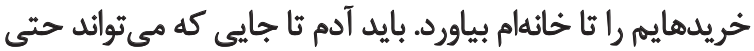

دستوياشكسته كارش را انجام دهد.

بر اساس تجربه سالمندان علاوه بر مديريت امور منزل،

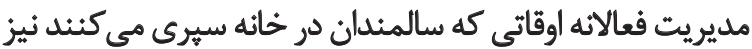

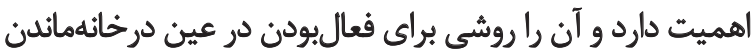

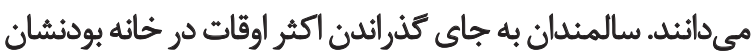

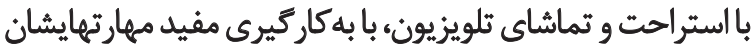

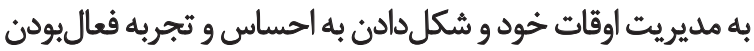

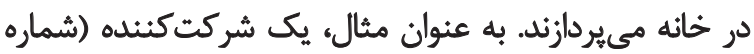

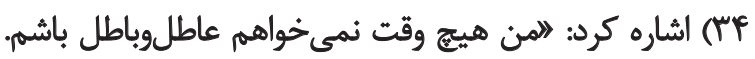

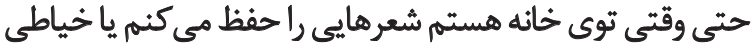

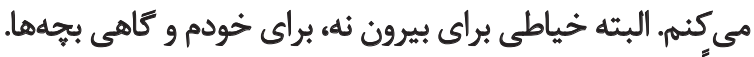

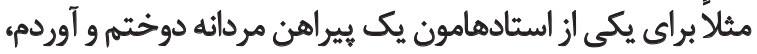

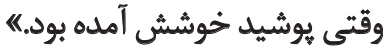

سالمندان با كمك نوشتن (اعم از خاطره يا يادداشت شخصى)

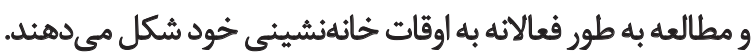

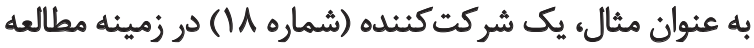

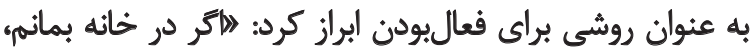

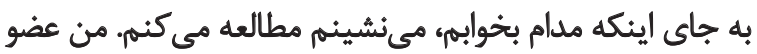

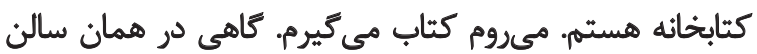

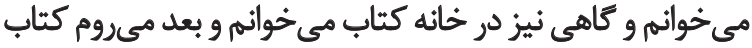

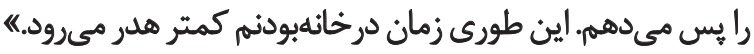

فوق العاده است كه مي تونم انجام بدم.《

كاهى سالمندان بر اساس توانايىها و استعدادهاى قبلى كه باديا

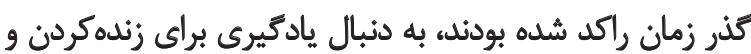

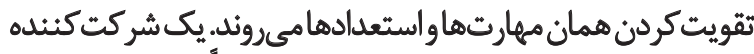

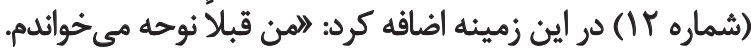

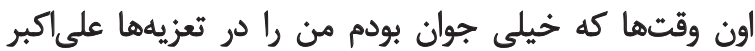

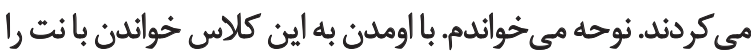

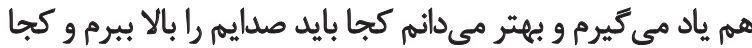

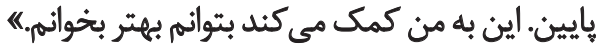

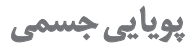

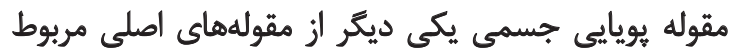

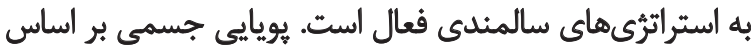

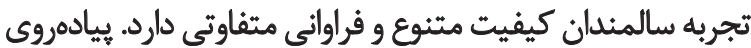

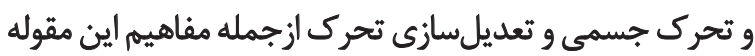

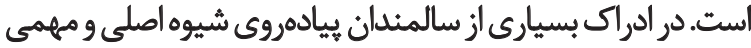

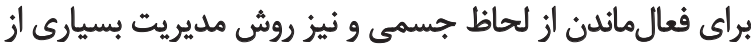

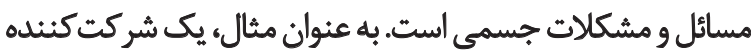

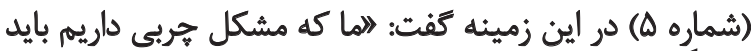

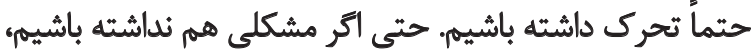

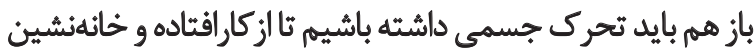

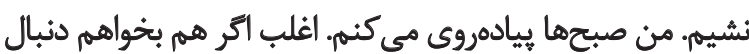

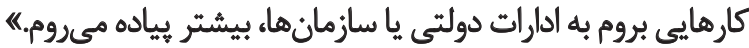

در ادراك بخشى از سالمندان براى فعالماندن از لحاظ

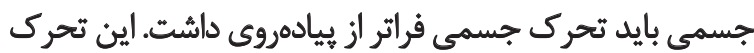

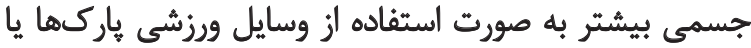

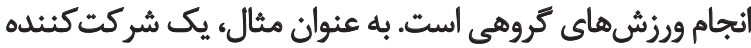

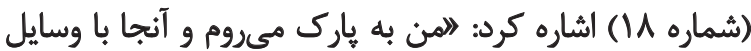

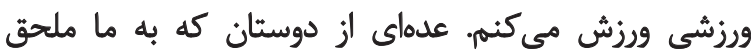

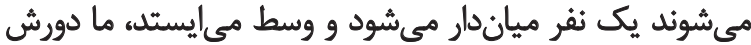
حلقه مئنيم و حركاتى راكه او انجام مي دهد انجام مي دهيه.

نكته جالب اينجاست كه بسيارى از سالمندان با وجود شرايط

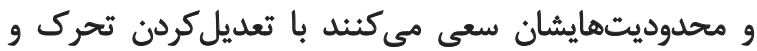

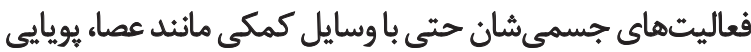

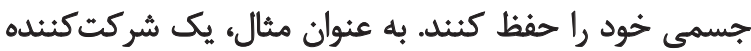

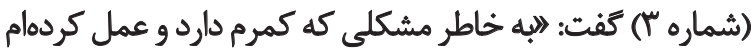

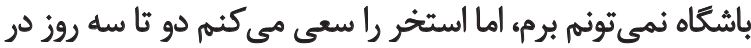

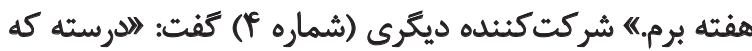

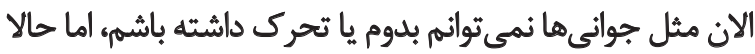

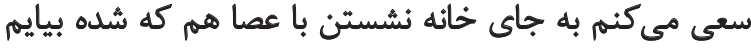

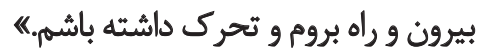


سالمندى فعال را با ديدكاه تفهيمى مدنظر قرار داده است. اين

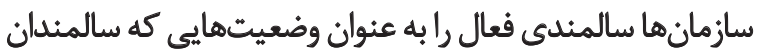

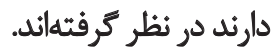
مثلأ سلامت را به معناى وضعيت سلامت جسمى و و عملكردى درى

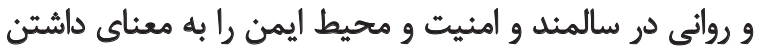

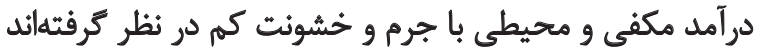

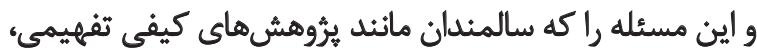

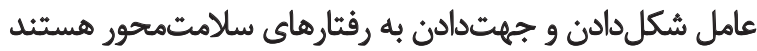

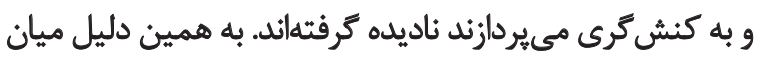

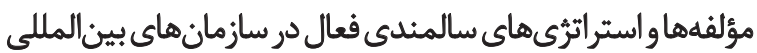

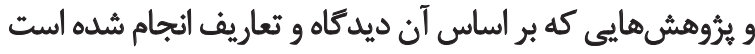

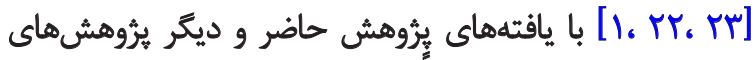

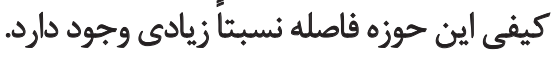

يُّوهشهاى كيفى در درك سالمندى فعال هم به يافتههاى

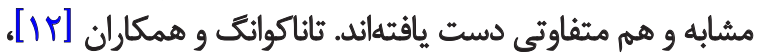

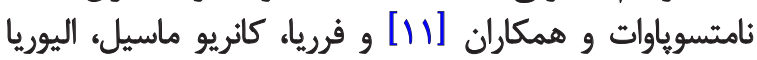

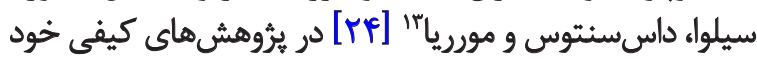

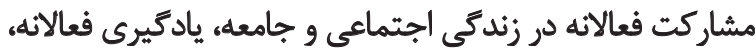

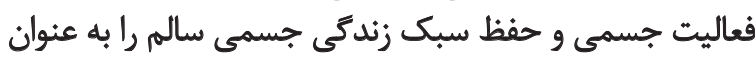

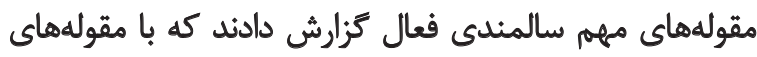

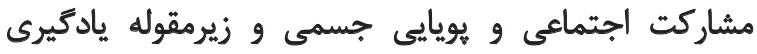
اشتراكات قابل توجهى دارند.

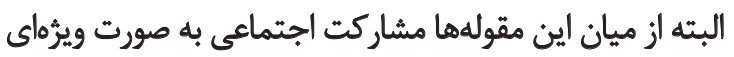

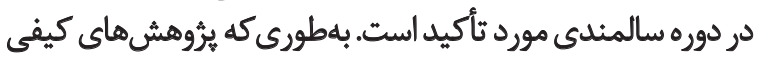

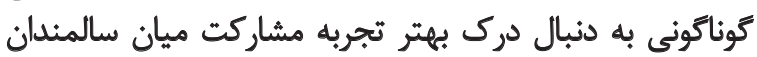

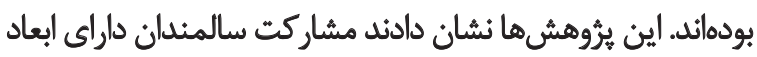

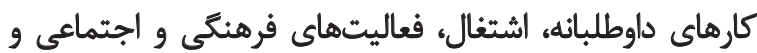

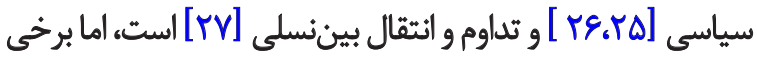

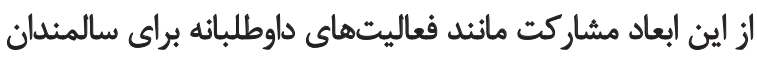

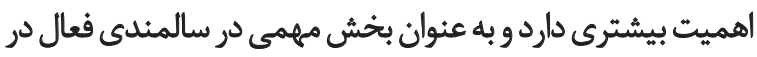

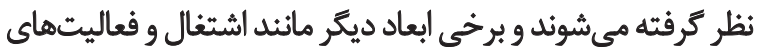

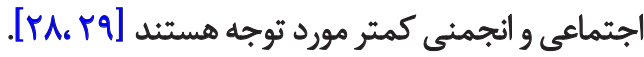

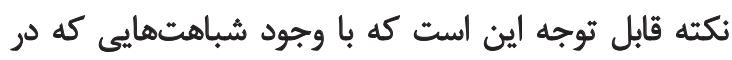

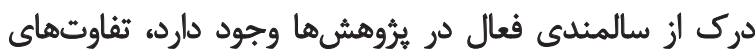

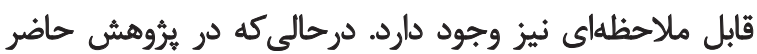

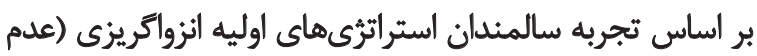

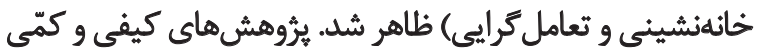

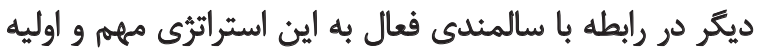

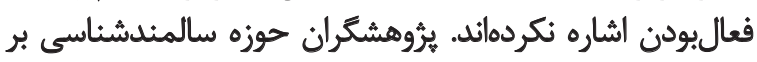

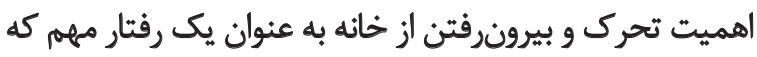

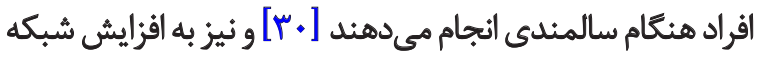

13. Ferreria, Carnerio Maciel, Oliveira Silva, Dos Santos \& Moreira
در تجربه بسيارى از سالمندان كه سعى مي كنيند فعال باشند،

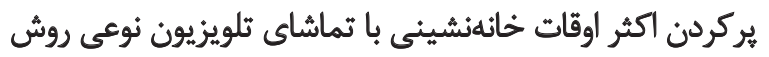

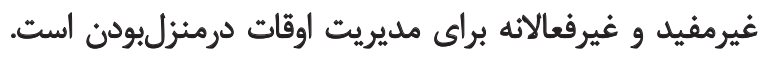

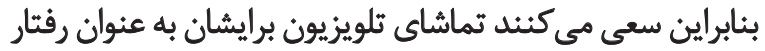

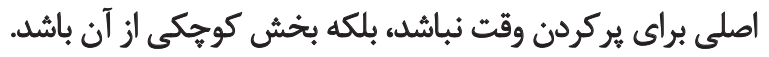

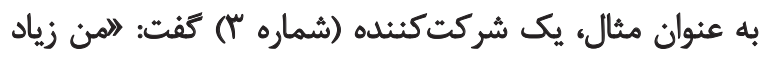

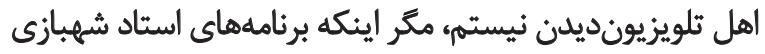

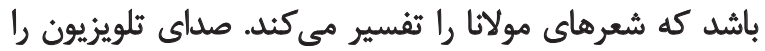

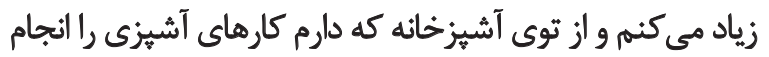

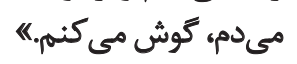

بر اساس يافتههاى برّوهش حاضر سالمندان ساكن در جامعانه

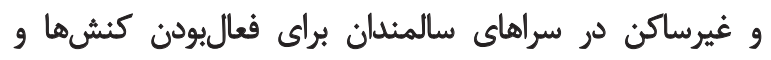

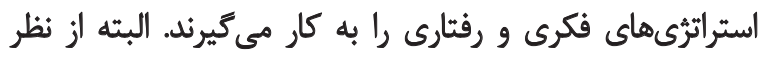

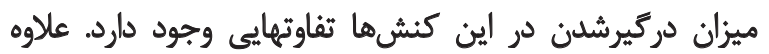

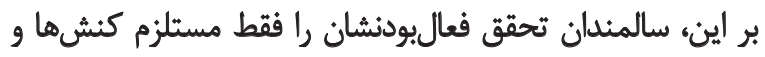

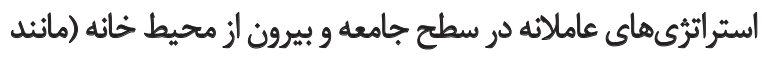

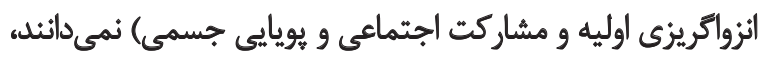

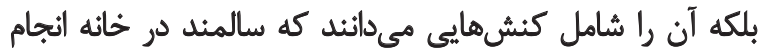

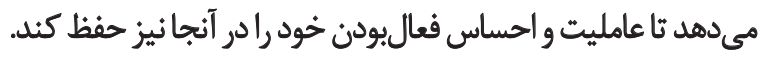

ثب

همان كونه كه يافتههاى برؤهش حاضر نشان داد روش برها و

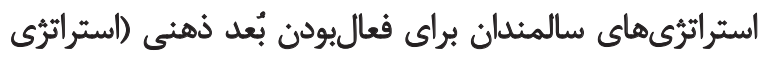

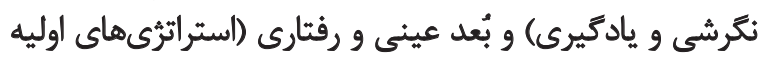

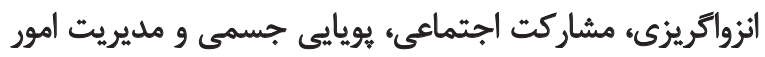

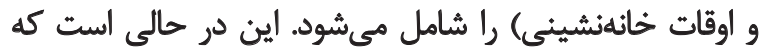

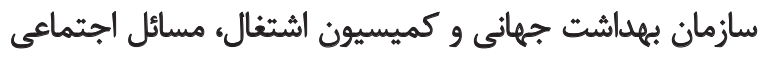

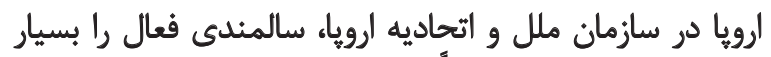

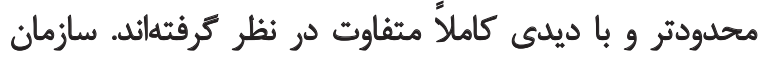

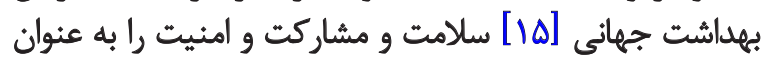

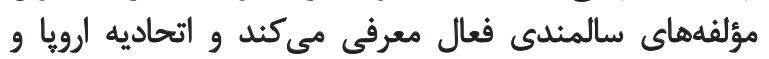

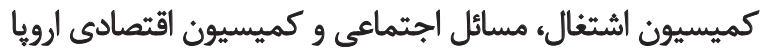

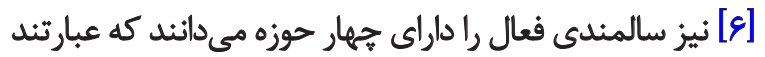

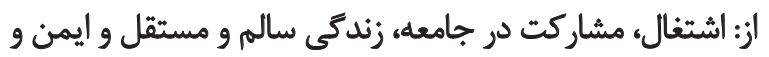

$$
\text { محيطى براى فعاليت سالمند. }
$$

بررسى اين تعاريف و مؤلفههاى مطرحشده توسط سازمانها

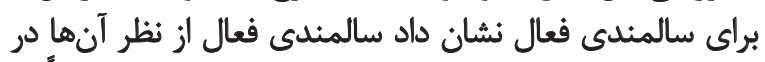

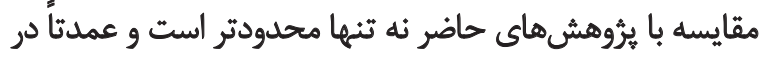

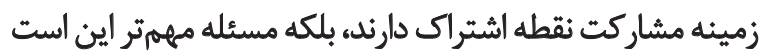

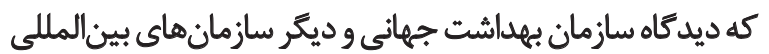

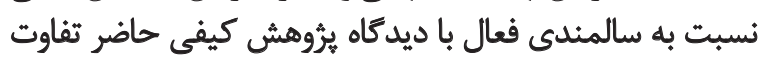

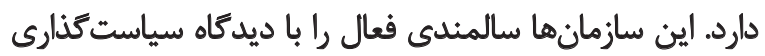

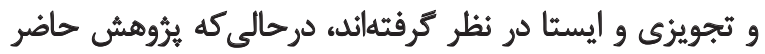


علاقه خودشان اشاره كرده بودند. در نقطه مقابل بينش فعالانه،

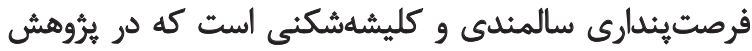

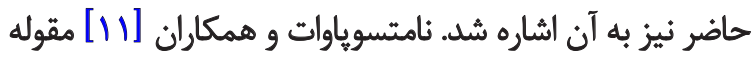

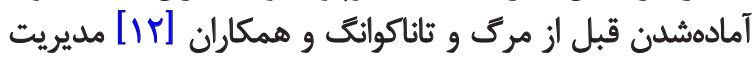

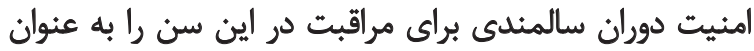

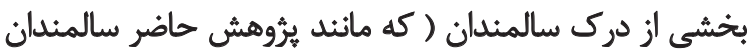
• ع ساله و بالاتر بودند) از سالمندى فعال بيان كردهاند.

اين امر نشاندهنده اين است كه در فرهنك آن جامعه (تايلند)

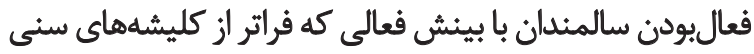

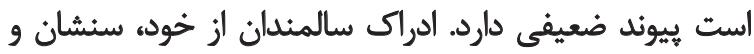

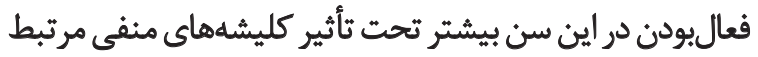

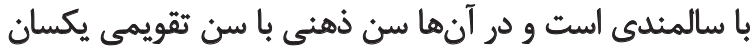

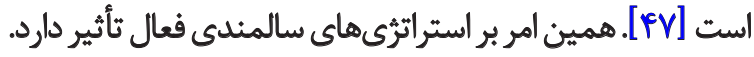

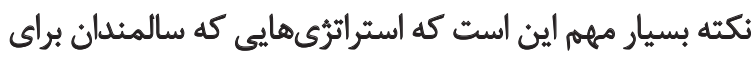

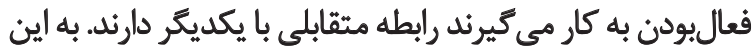

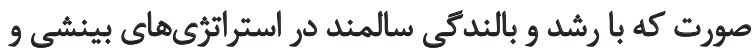

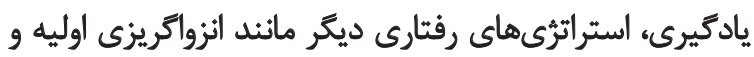

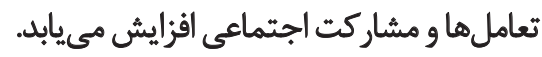

به عنوان مثال، بر اساس مطالعه كيفى كيرولده مويل،

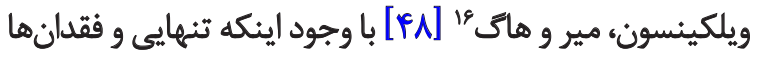

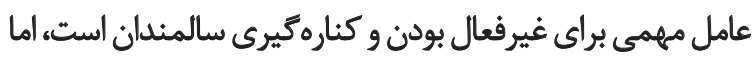

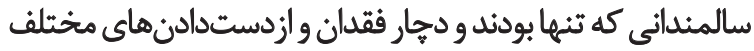

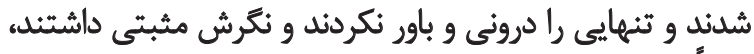

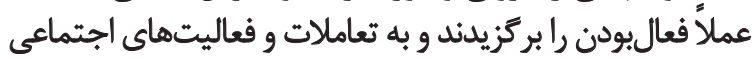

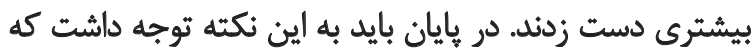

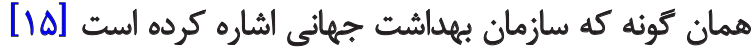

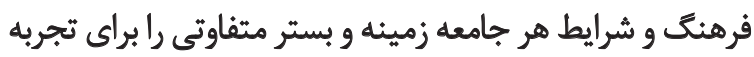

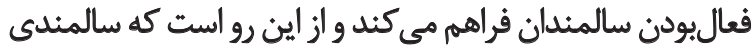

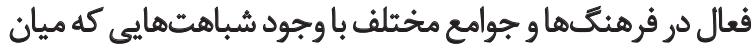
آنها وجود دارد، تفاوتهاى قابل توجهى نيز داردارد

\section{تثيجلكيرى نمهايي}

امروزه در نحوه درك و برخورد با بديده سالمندى جمعيت

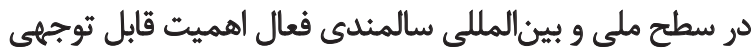

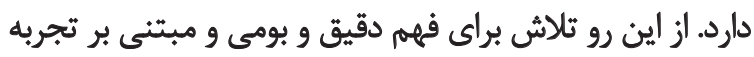

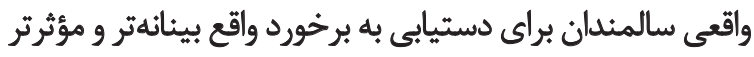

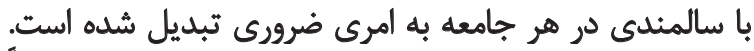

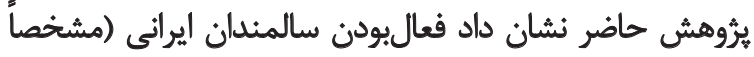

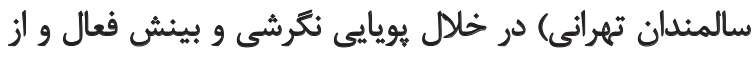

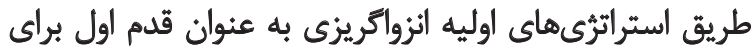

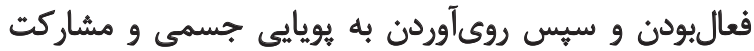

16. Kirkevold, Moyle, Wilkinson, Meyer \& Hauge

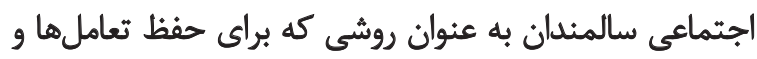

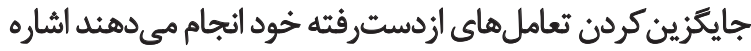

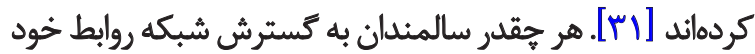

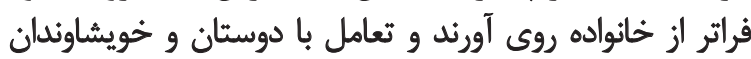

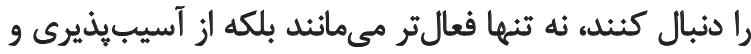

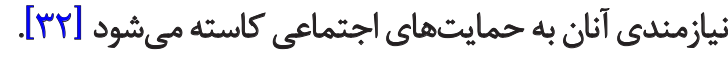

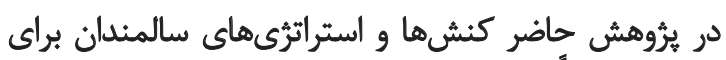

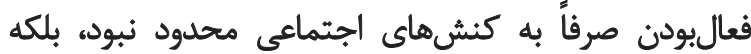

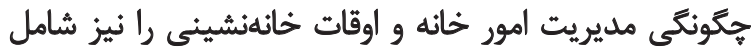

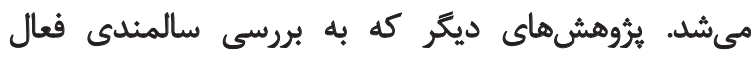

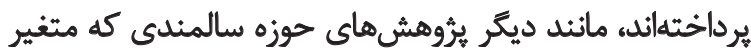

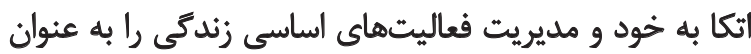

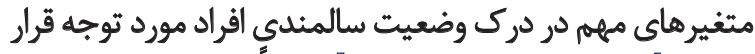

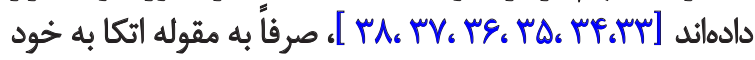

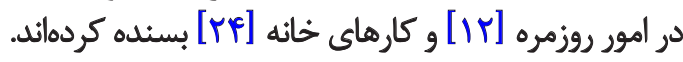
در حوزه سالمندى فعال نيز وضعيت مديريت امور خانهوزندئى سري

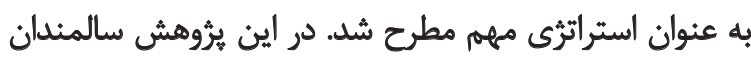

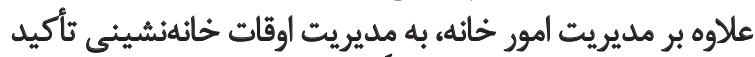

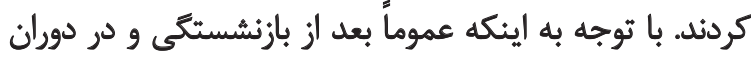

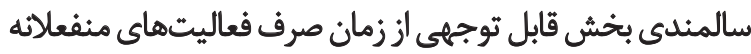

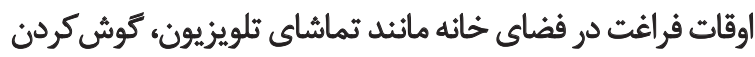

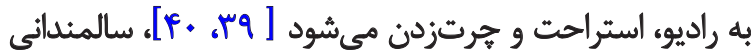

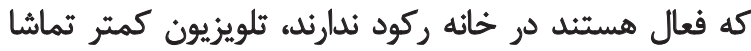

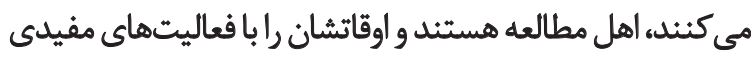
مائند كارهاى هنرى و مهارتى ير مي وكنئد.

به عبارتى همسو با يُؤهش حاضر، فعالانه عمل كردن در اوقات

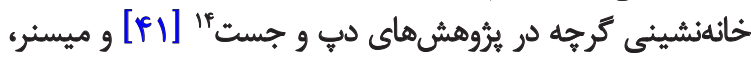

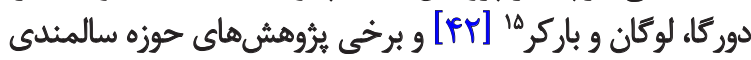

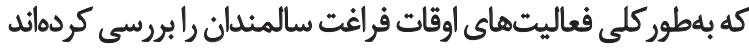

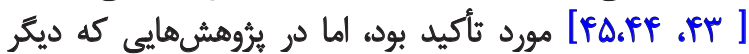

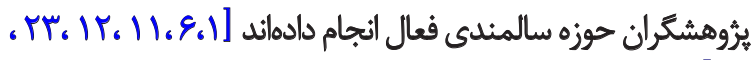

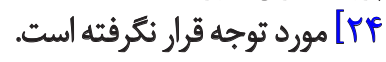

از نظر شركتكنيدكان يروهش حاضر فعالبودن نه تنهها از

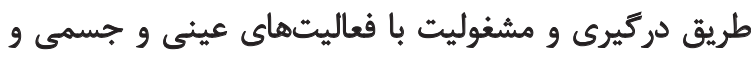

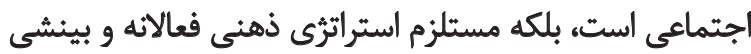

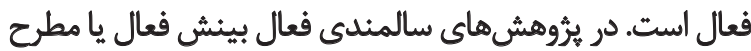

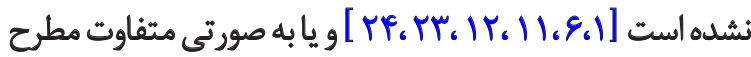

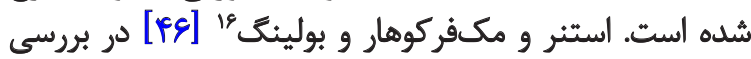

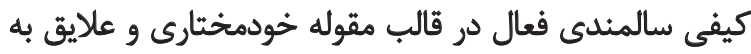

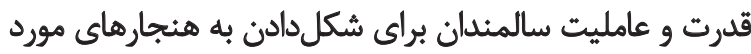




\section{References}

[1] Buys L, Miller E. The meaning of active aging to older Australian: exploring the relative importance of health, participation and security. Paper presented at: The $39^{\text {th }}$ Australian Association of Gerontology Conference. 2006 Aug 06; Sydney, Australia.

[2] Van Dyk S. Turner ME. Active, productive and healthy aging in Germany and the United States. Paper presented at: Ageing and Society Conference. 8-9 November 2011; Berkeley, USA.

[3] Fernandez-Ballesteros E, Robine JM , Walker A, Kalache A. Active aging: A global goal. Current Gerontology and Geriatric Research. 2013; 1-4. doi: 10.1155/2013/298012

[4] Moulaert T, Paris M. Social policy on aging: The case of active aging as a theatrical metaphor. International Journal of Social Science Studies. 2013; 1(2):113-123. doi: 10.11114/ijsss.v1i2.141

[5] Jhala N, Christian A. Active aging. International Journal of $\mathrm{Hu}-$ manities and Social Science Intervention 2013; 2(1):1-4.

[6] United Nations Economic Commission for Europe. Introducing the active aging index: Policy brief. Geneva: United Nations; 2013.

[7] Hutchison T, Morrison P, Mikhailovich K. A review of the literature on active ageing. Canberra: Healthpact Research Center for Health Promotion and Well-being; 2006.

[8] De Donder L, Dury S, De Witte N, Smetcoren AS, Buffel T, Verte D. Active aging: Exploring social participation in Belgium. Paper presented at: The $21^{\text {st }}$ Nordic Congress of Gerontology. 2012 June 11; Copenhagen, Denmark.

[9] Hirari H, Kndo K, Kawachi I. Social determinants of active aging: differences in mortality and the loss of healthy life between different income levels among older Japanese. Current Gerontology \& Geriatrics. 2012; 1-9. doi: 10/1155/2012/701583.

[10] Fernandez-Ballesteros R, Angeles Molina M, Schettini R, Del Rey AL. Promoting active aging through university programs for older adults. GeroPsuch. 2012; 25(3):145-54. doi: 10.1024/16629647/a000064

[11] Namtsupawat W, Kamnusailapa P, Sritanyarat W, Wongthanawasu S. Family relationships, role and meaning of active aging among rural northeastern Thai elders. Pacific Rim International Journal of Nursing Research. 2010; 14(2):137-148.

[12] Thanakwang K, Isaramalai S, Hattkhakit U. Thai cultural understandings of active ageing from the perspectives of older adults: A qualitative study. Pacific Rim International Journal of Nursing Research. 2014; 18(2):152-165.

[13] Walker A. Strategy for active ageing. International Social Security Review. 2002; 55(1):121-139. doi: 10.1111/1468-246x.00118

[14] Vidovicova L. To be active or not to be active: That is the question: The preference model of activity in advanced age. Journal of Ageing International. 2005; 30(4):343-362. doi: 10.1007/s12126005-1020-0

[15] World Health Organization. Active aging: A policy framework. Geneva: World Health Organization; 2002.

[16] Mohammad Pour A. [Against method: Rationale and design of qualitative methodology (Persian)]. Tehran: Jame'e Shenasan Publications; 2010

[17] Richards L, Morse JM. README FIRST for a user's guide to qualitative methods. London: SAGE publication; 2013.

$$
\begin{aligned}
& \text { اجتماعى و در عين حال فعال مائدن در مديريت امور و اوقات } \\
& \text { خانهنشينى تحقق مى }
\end{aligned}
$$

فعالبودن سالمندان در كرو استراترىهايى است كه در سه دانه

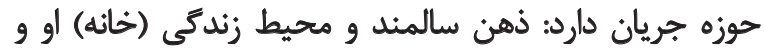

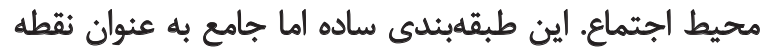

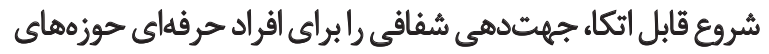

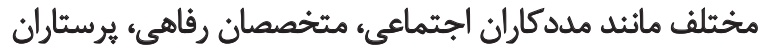

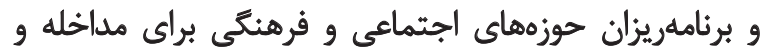

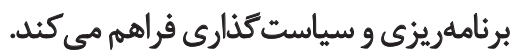

هر هند إثروهش حاضر اولين ثلاش براى درك بهتر تجربه

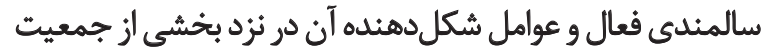

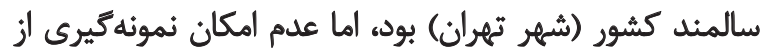

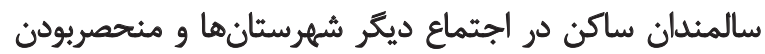

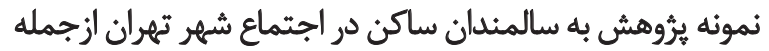

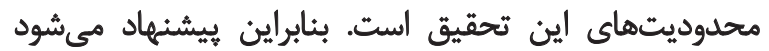

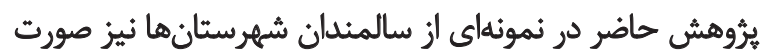

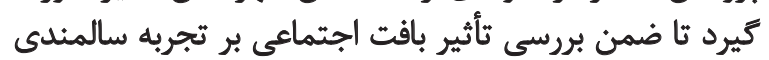

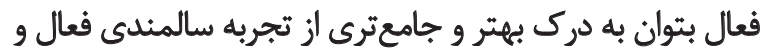

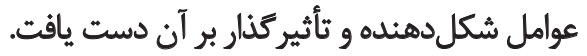

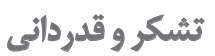

اين مطالعه بخشى از يايان نامه مقطع دكترى نويسنده اول در

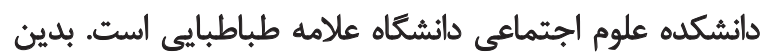

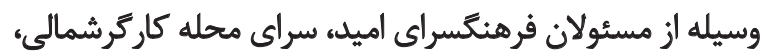

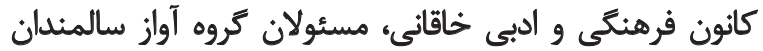

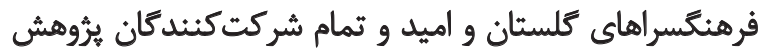
سياسگزارى مى شئود. 
[18] Corbin JM, Strauss A. Grounded theory research: Procedures, canons, and evaluative criteria. Qualitative Sociology. 1990; 13(1):3-21. doi: 10.1007/bf00988593

[19] Hariri N. [Principles and methods of qualitative research (Persian)]. Tehran: Science and Research Branch, Islamic Azad University Press; 2006

[20] Strauss A, Corbin J. Basics of qualitative research: Techniques and procedures for developing grounded theory. London: Sage Publication; 1998.

[21] Schwandt TA, Lincoln YS, Guba EG. Judging interpretations: but is it rigorous? Trustworthiness and authenticity in naturalistic evaluation. New Directions for Evaluation. 2007; 114:11-25. doi: 10.1002/ev.223

[22] Tareque IM, Hoque N, Mahfuza Islam R, Kawahara K, Sugawa M. Relationships between the active aging index and disability-free life expectancy: A case study in the Rajshahi District of Bangladesh. Canadian Journal on Aging. 2013; 32(4):417-432. doi: $10.1017 /$ s0714980813000494

[23] Zasimova L, Sheluntcova M. Measuring active aging government policy planning: A case of Russia. New York: Higher School of Economics. 2014 January. 30 p. Research No. WP BRP 11/ PA/2014. doi: 10.2139/ssrn.2385832

[24] Ferreria OGL, Carnerio Maciel S, Oliveira Silva A, Dos Santos WS, Moreira MAS. Active aging from the perspective of aged individuals who are functionally independent. Revista da Escola de Enfermagem da USP. 2010; 44(4):1065-1069. doi: 10.1590/s008062342010000400030

[25] Mars GMJ, Kempen IJM, Mesters I, Proot I M, Van Eijk J THM. Characteristics of social participation as defined by older adults with a chronic physical illness. Disability and Rehabilitation. 2008; 30(17):1298-308. doi: 10.1080/09638280701623554

[26] Pavelek L. How can volunteering improve the individual and social life of the elderly. Social and Natural Sciences Journal. 2012; 6:21-24. doi: 10.12955/snsj.v6i0.316

[27] Cooper MR. The inevitable aging of the population and the implications of prolonging employment for older adults [MSc. thesis]. Perth: Edith Cowan University; 2005.

[28] Darvishpoor Kakhki A, Abed Saeedi ZH, Abbaszadeh A. [Social participation, barriers and related factors in older people in Tehran (Persian)]. Journal of Health Promotion Management. 2014; 3(4):65-73.

[29] Robertson G. The contribution of volunteering and a wider asset based approach to active aging and intergenerational solidarity in Europe. Journal of Working with Older People. 2013; 17(1):7-18. doi: 10.1108/13663661311312539

[30] Mollenkopf H, Heiber A, Wahl HW. Continuity and change in older adults perceptions of out of home mobility over ten years: a qualitative-quantitative approach. Ageing \& Society. 2011; 31(5):782-802. doi: 10.1017/S0144686X10000644

[31] Conway F, Magal C, Jones S, Fiori K, Gillespie M. A six-year follow up study of social network changes among AfricanAmerican, Caribbean and U.S born Caucasian urban older adults. International Journal of Aging and Human Development. 2013; 76(1):1-27. doi: 10.2190/ag.76.1.a

[32] Mohammadi E. [Investigating the relationship between social networks and health characteristics of elderly retirees; Members of national retirement and retirement education in Karaj (Per- sian)] [MSc. thesis]. Tehran: University of Social Welfare and Rehabilitation Sciences; 2012

[33] Masoomi N, Jafroodi S, Ghanbari A, Kazem Nejad E. [Assessment of retired elderly's people autonomy and its affecting factors in Rasht (Persian)]. Holistic Nursing and Midwifery Journal. 2011; 21(1):46-51.

[34] Moeini B, Barati M, Jalilian F. [Factors associated with the functional independence level in older adults (Persian)]. Hormozgan Medical Journal. 2012; 15(4):318-326.

[35] Santos JLF, Lebrão ML, Duarte YAO, Lima FD. Functional performance of the elderly in instrumental activities of daily living: an analysis in the municipality of São Paulo, Brazil. Cadernos de Saúde Pública. 2008; 24(4):879-886. doi: 10.1590/s0102$311 \times 2008000400019$

[36] Nourhashemi F, Andrieu S, Gillette-Guyonnet S, Vellas B Albarede JL, Grandjean H. Instrumental activities of daily living as a potential marker of frailty: A study of 7364 communitydwelling elderly women (the EPIDOS Study). Journal of Gerontology and medical Sciences. 2001; 56(7):448-453. doi: 10.1093/ gerona/56.7.m 448

[37] Mathuranath PS, George A, Cherian PJ, Mathew R, Sarma S. Instrumental activities of daily living scale for dementia screening in elderly people. International Psychogeriatrics. 2005. 17(3):461474. doi: $10.1017 /$ s1041610205001547

[38] Tang Z, Wang HX, Meng C, Wu XG, Ericsson K, Winbald B, Pei JJ. The prevalence of functional disability in activities of daily living and instrumental activities of daily living among elderly Beijing Chinese. Archives of Gerontology and Geriatrics. 1999; 29(2):115-125. doi: 10.1016/s0167-4943(99)00026-6

[39] Gauthier AH, Smeeding TM. Time use at older ages. Journal of Research on Aging. 2003; 25(3):247-274. doi $10.1177 / 0164027503025003003$

[40] Chamanpira M, Farahani A, Jalali Farahani M. [Older adults leisure time and physical activity with emphasis on sport equipment provided by Tehran Municipality in 2010 (Persian)]. Iranian Journal of Ageing. 2014; 9(3):179-183.

[41] Depp CA, Jeste DV. Definitions and predictors of successfu aging: A comprehensive review of larger quantitative studies. American Journal of Geriatric Psychology. 2006; 14(1):6-20. doi: 10.1097/01.jgp.0000192501.03069.bc

[42] Meisner BA, Dogra S, Logan A J, Baker J, Weir PL. Do or Decline: Comparing the effects of physical inactivity on biopsychosocial component of successful aging. Journal of health psychology. 2010; 15(5): 688-696. doi: 10.1177/1359105310368184

[43] Chang MO, Kaufman D, Ireland A. Personal background and differences in urban older adults' leisure time use. British Journal of Education, Society \& Behavioral Science. 2015; 9(4):300-317. doi: $10.9734 /$ bjesbs/2015/17886

[44] Kikuchi H, Inoue S, Sugiyama T, Owen N, Oka K, Nakaya T, et al. Ditict association of different sedentary behaviors with healthrelated attributes among older adults. Preventive Medicine. 2014; 67:335-339. doi: 10.1016/j.ypmed.2014.08.011

[45] Espinel PT, Chau JY, Van der Ploeg H, Merom D. Older adults time in sedentary, litr and moderate intensity activities and correlates: Application of Australian Time Use Servey. Journal of Science and Medicine in Sport. 2015; 18(2):161-166. doi: 10.1016/j jsams.2014.02.012 
[46] Stenner P, McFarqhuhar T, Bowling A. Older people and active aging: Subjective aspects of aging actively and becoming old. Journal of Health Psychology. 2011; 16(3):467-477. doi: $10.1177 / 1359105310384298$

[47] Sadegh Moghadam L, Foroughan M, Mohammadi F, Ahmadi F. Farhadi A, Nazari S, et al. [Aging perception in older adults: review paper (Persian)]. Journal of ageing. 2016; 10(4):202-209.

[48] Kirkevold M, Moyle W, Wilkinson C, Meyer J, Hauge S. Facing the challenges of adapting to a life alone in old age: Influence of losses. Journal of Advanced Nursing. 2012; 69(2):394-403. doi: 10.1111/j.1365-2648.2012.06018.x 